\title{
Mechanistic Insights into Selective Oxidation of Polyaromatic Compounds using RICO Chemistry
}

Ewa Nowicka, ${ }^{\mathrm{a}, \mathrm{b}^{*}}$ Niamh W. Hickey, ${ }^{\mathrm{b}}$ Meenakshisundaram Sankar, ${ }^{\mathrm{b}}$ Robert L. Jenkins, ${ }^{\mathrm{b}}$

David W. Knight, ${ }^{\mathrm{b}}$ David J. Willock, ${ }^{\mathrm{b}^{*}}$ Graham J. Hutchings, ${ }^{\mathrm{b}}$ Manuel Francisco ${ }^{\mathrm{c} \dagger}$ and Stuart

H. Taylor ${ }^{b}$

${ }^{a}$ Institut für Chemie, Technische Universität Berlin, Straße des 17. Juni 124, 10623 Berlin, Germany.

${ }^{b}$ Cardiff Catalysis Institute, School of Chemistry, Cardiff University, Main Building, Park Place, Cardiff, CF10 3AT, UK.

${ }^{c}$ ExxonMobil, Research \& Engineering Company, 1545 Route 22 East, Annandale, New Jersey 08801, USA.

*Corresponding Authors: $\quad$ Email: nowicka@tu-berlin.de $\quad$ Tel: +49 (0)303 1424097

willockdj@cardiff.ac.uk Tel: +44 (0)29 2087779

${ }^{\dagger}$ Deceased March 9, 2016. 


\begin{abstract}
Ruthenium ion catalyzed oxidation (RICO) of polyaromatic hydrocarbons (PAHs) has been studied in detail using experimental and computational approaches to explore the reaction mechanism. DFT calculations show that regioselectivity in these reactions can be understood in terms of the preservation of aromaticity in the initial formation of a [3+2] metallocycle intermediate at the most isolated double bond. We identify two competing pathways: C-C bond cleavage leading to a dialdehyde and $\mathrm{C}-\mathrm{H}$ activation followed by $\mathrm{H}$ migration to the $\mathrm{RuO}_{\mathrm{x}}$ complex to give diketones. Experimentally, the oxidation of pyrene and phenanthrene has been carried out in monophasic and biphasic solvent systems. Our results show that diketones are the major product for both phenanthrene and pyrene substrates. These diketone products are shown to be stable under our reaction conditions so that higher oxidation products (acids and their derivatives) are assigned to the competing pathway through the dialdehyde. Experiments using ${ }^{18} \mathrm{O}$-labelled water do show incorporation of oxygen from the solvents into products, but this may take place during the formation of the reactive $\mathrm{RuO}_{4}$ species rather than directly during PAH oxidation. When the oxidation of pyrene is carried out using $\mathrm{D}_{2} \mathrm{O}$ a kinetic isotope effect (KIE) is observed implying that water is involved in the rate determining step leading to the diketone products.
\end{abstract}

Keywords: RICO, polynuclear aromatic hydrocarbons, pyrene, phenanthrene, DFT, reaction mechanism, catalysis 


\section{Introduction}

In 1953, Djerassi and Engle reported a ruthenium tetroxide catalytic system for the oxidation of a number of organic substrates. ${ }^{[1]}$ This discovery opened up an entirely new area of chemistry in the oxidation of organic compounds now known as ruthenium ion catalysed oxidation (RICO). In RICO chemistry, $\mathrm{RuO}_{4}$ is generated in situ by the combination of a ruthenium ion and an oxidizing agent ${ }^{[2]}$ usually in a biphasic mixture of dichloromethane and water. Following on from this early work, Sharpless et al. ${ }^{[3]}$ reported that the addition of acetonitrile as a co-solvent improves both catalytic activity and selectivity for the oxidation of alkenes to carboxylic acids so that much lower metal loadings could be used. It was suggested that deactivation of the catalyst takes place when carboxylate species, formed as side-products during these reactions, coordinate to the $\mathrm{Ru}$ centre, rendering it inactive. Acetonitrile can compete with the carboxylate for vacant coordination sites at $\mathrm{Ru}$ and so prevent deactivation. To date RICO has been reported to be effective for many reactions, including the dihydroxylation of olefins, ${ }^{[4]}$ dehydrogenation of alcohols and amines, ${ }^{[5]}$ selective monooxidation of vicinal diols ${ }^{[6]}$ keto- $\alpha$-hydroxylation, ${ }^{[7]}$ oxidative cyclization of polyenes, ${ }^{[8]}$ oxidative cleavage of double and triple bonds, ${ }^{[9]}$ oxidation of heteroatoms ${ }^{[10]}$ and oxidation of saturated hydrocarbons and aromatic hydrocarbons. ${ }^{[11]}$

The strong oxidising power of $\mathrm{RuO}_{4}$ can be understood from the redox potentials measured for the various electrochemical reduction steps in the series: ${ }^{[12]}$

$$
\mathrm{RuO}_{4} \underset{1.00 \mathrm{~V}}{\longrightarrow} \mathrm{RuO}_{4}{ }^{-} \underset{0.59 \mathrm{~V}}{\longrightarrow} \mathrm{RuO}_{4}{ }^{2-} \underset{0.20 \mathrm{~V}}{\longrightarrow} \mathrm{RuO}_{2} \text { (aq.) }
$$

The two electron reduction from $\mathrm{Ru}(+8)$ to $\mathrm{Ru}(+6)$ giving a total reduction potential of $1.59 \mathrm{~V}$ while the $\mathrm{Ru}(+6)$ to $\mathrm{Ru}(+4)$ step gives only $0.20 \mathrm{~V}$. Hence in the RICO system, a strong oxidant 
capable of maintaining $\mathrm{Ru}$ in oxidation state +8 while being unreactive with the organic substrate is required. A convenient choice is sodium periodate, $\mathrm{NaIO}_{4}$, which we employ in this work. ${ }^{[3]}$

Bakke and Frøhaug ${ }^{[13]}$ investigated the mechanism of $\mathrm{RuO}_{4}$ oxidation of saturated hydrocarbons and found that the reaction is first order in both substrate and catalyst. They also showed that oxidation occurs preferentially at tertiary carbon atoms, but with a dependence on solvent that suggests that carbocations are not generated in the reaction pathway. The strong primary kinetic isotope effect (KIE), found from a comparison of normal and deuterated substrates, was explained by a two-step mechanism. Here hydrogen is abstracted from the alkane to form a ruthenium ester with a reduction of the metal from $\mathrm{Ru}(+8)$ to $\mathrm{Ru}(+6)$. The precursor to this ester species is in pre-equilibrium with the reagents. Alcohol products are then formed on hydrolysis of the ruthenium ester intermediate.

In the area of polyaromatic hydrocarbons (PAHs), RICO chemistry has largely been used for the complete digestion of aromatic compounds as part of a quantitative aromatic/alkane ratio determination for heavy crude oil fractions. ${ }^{[14]}$ We have previously reported how RICO chemistry can be used in a more controlled manner such that partial oxidation of the PAH takes place to generate aldehydes, ketones and acid functional groups with low levels of oxidation of any alkyl substituents. ${ }^{[15]}$ We further explored this subject by studying the role of aromatic ring number in reaction kinetics and product distribution using RICO chemistry. ${ }^{[16]}$ In the present contribution, we aim to use a combination of density functional theory (DFT) calculations and isotopic labelling experiments to identify the mechanistic steps that lead to these products in the initial stages of the oxidation reaction using pyrene and phenanthrene as exemplar PAH molecules. 
Previous findings related to RICO mechanism for PAH oxidation suggested that $\mathrm{C}-\mathrm{C}$ bond scission is involved in the first step of the reaction. Plietker suggested that the mechanism may be similar to the oxidative cleavage of double bonds, where $\mathrm{RuO}_{4}$ adds to a double bond to form a ruthenium (VI) compound. ${ }^{[17]}$ Frenking and co-workers have used density functional theory calculations to show that $\mathrm{RuO}_{4}$ will form stable ruthenium(VI) adducts with ethene through a [3+2] cycloaddition of $\mathrm{RuO}_{4}$ across the double bond. ${ }^{[18]} \mathrm{C}-\mathrm{C}$ bond cleavage then leads to formaldehyde. A similar [3+2] initial complex has also been found for oxidative cyclisation for both $\mathrm{RuO}_{4}$ and the related $\mathrm{OsO}_{4}$ and $\mathrm{MnO}_{4}{ }^{-}$oxo complexes. [19]

In the present work, we show how a [3+2] cycloaddition intermediate can be formed for both of the model PAH compounds pyrene and phenanthrene. The experimentally observed selectivity for oxidation at the 4,5 and 9,10-positions in pyrene is consistent with the cycloaddition taking place at the ring position that least disturbs aromaticity and the same argument can be used to understand the experimentally observed selectivity for phenanthrene. We also show that $\mathrm{C}-\mathrm{H}$ activation is competitive with $\mathrm{C}-\mathrm{C}$ cleavage in these adducts explaining the experimental observation that a dione is the major product observed in the early stages of reaction. Experimental selectivity data is consistent with this model and shows that the dione products are relatively stable under our experimental conditions, but that the dialdehydes are readily oxidised further to acids. Reactions using diones as substrate confirm the stability of this PAH oxidation product. Using experiments with $\mathrm{D}_{2} \mathrm{O}$ included in the solvent mix we show that water is implicated in the $\mathrm{H}$ atom removal leading to the dione product through kinetic isotopic effect experiments.

\section{Computational and experimental details}


All calculations have been carried out using the Gaussian09 software suite ${ }^{[20]}$ at the hybrid DFT (B3LYP ${ }^{[21]}$ ) level with a 6-31G(d,p) basis set on atoms other than Ru. The LANL2DZ basis set is used for ruthenium along with the corresponding effective core potential (ECP). These potentials also conveniently account for the core contraction due to relativistic effects. Single point energy calculations were also carried out for some key structures using the metaGGA hybrid functional, M06 ${ }^{[22]}$ with the same basis set as discussed above. This served as a cross check on the effect of the choice of functional on the relative barrier energies reported. The M06 functional has been shown to perform well for barrier calculations on a large data set of organic reactions. ${ }^{[23]}$ However, for transition metal complexes the ordering of alternative multiplicities appears reliable with B3LYP. ${ }^{[24]}$

Optimisation criteria were set so that forces on any atom will be below 0.0045 a.u. and the root mean square (rms) force across all atoms will be below 0.003 a.u.. Transition state searches were carried out using a constrained optimisation procedure to follow a reaction pathway defined using two atoms which are involved in bond breaking or formation for the particular elementary step of the reaction. Scans along the reaction coordinates typically used atom translations of $0.1 \AA$. This was followed by a transition state search using the normal modes calculated at the highest point on the coordinate scan. Minima and transition states were confirmed using frequency calculations with transition states accepted only if a single imaginary mode was present. Imaginary modes were visualised to ensure that the corresponding motion was consistent with the reaction step being studied.

The binding energy, $E_{b}$, for the [3+2] complex discussed in the Results section was calculated using the relation:

$E_{b}=E_{[3+2]}-E_{R u O 4}-E_{P A H}$ 
where $E_{[3+2]}$ is the energy of the [3+2] complex formed and $E_{R u O 4}$ and $E_{P A H}$ are the energies of the $\mathrm{RuO}_{4}$ oxidising agent and the polyaromatic hydrocarbon in isolation. All reaction energies are calculated relative to the relevant [3+2] complex. We report free energy differences, $\Delta \mathrm{G}$, based on the calculated electronic energy difference with the inclusion of zero point energy and vibrational entropy from the calculated real frequencies using the harmonic approximation along with the usual thermal corrections for rotational and translational degrees of freedom at $298 \mathrm{~K}$.

Monophasic and biphasic oxidation reactions of PAHs (0.164 mmol) were carried out at 295 $\mathrm{K}$ and $308 \mathrm{~K}$, respectively. Temperature control was achieved using a jacketed reactor (thermostated water bath, Julabo F25-ME Refrigerated/Heating Circulator). In a typical reaction, the reactor was charged with $0.164 \mathrm{mmol}$ of substrate and the appropriate amount of solvent and the reactor temperature set at the required temperature. Solvent compositions of acetonitrile $(\mathrm{MeCN})(20 \mathrm{ml})$ and $\mathrm{H}_{2} \mathrm{O}(10 \mathrm{ml})$ were used to give the monophasic system and acetonitrile $(7 \mathrm{ml})$, dichloromethane $(16 \mathrm{ml})$ and $\mathrm{H}_{2} \mathrm{O}(7 \mathrm{ml})$ were used for the biphasic solvent system. To this mixture an aqueous solution of $\mathrm{NaIO}_{4}(280 \mathrm{mg}, 1.312 \mathrm{mmol}$ dissolved in $10 \mathrm{ml}$ $\left.\mathrm{H}_{2} \mathrm{O}\right)$ was added and stirred for $1 \mathrm{~min}$ at a speed of $500 \mathrm{rpm}$. Then $\mathrm{RuCl}_{3} \cdot \mathrm{xH}_{2} \mathrm{O}(2.5 \mathrm{mg}, 0.012$ mmol) was added as catalyst and stirring recommenced. The addition of the ruthenium chloride was taken as time zero for the reaction. During the course of the reaction, small aliquots of the reaction mixture $(0.5 \mathrm{ml})$ were withdrawn at regular times and immediately quenched by the addition of an aqueous solution of $\mathrm{Na}_{2} \mathrm{SO}_{3}\left(0.1 \mathrm{ml}, 1.403 \mathrm{mmol}\right.$ of a solution in $\left.6 \mathrm{ml} \mathrm{H}_{2} \mathrm{O}\right)$ and quantitatively analyzed by gas chromatography (GC). To this end, $0.1 \mu$ of the solution was injected into the GC fitted with a VF-5ht (30 m, $0.25 \mathrm{~mm})$ column. For reactions with $\mathrm{H}_{2}{ }^{18} \mathrm{O}$, experiments were scaled down to give total solvent volumes of $3 \mathrm{ml}$, keeping the ratio of substrate: oxidant: catalyst constant. For HPLC-MS analysis, after the desired time, the reaction 
was quenched and the organic and aqueous layers separated. The organic layer was evaporated to dryness, and the resultant solid was redissolved in $1 \mathrm{ml}$ of acetonitrile and added to the external standard: benzophenone $\left(0.1 \mathrm{ml}, \mathrm{M}=0.01 \mathrm{~mol} \mathrm{l}^{-1}\right)$. For the aqueous layer, a portion of sample $(0.6 \mathrm{ml})$ was combined with acetonitrile $(0.4 \mathrm{ml})$ and benzophenone to make a total volume of $1.1 \mathrm{ml}$ prior to injection.

Gas Chromatography-Mass Spectrometry (GC-MS) analyses were performed using a Waters GCT premier instrument fitted with an Agilent HP-5MS column (30 m x $0.25 \mu \mathrm{m})$, carrier gas was $\mathrm{He}\left(1 \mathrm{ml} \mathrm{min}{ }^{-1}\right)$ and temperature was programmed from $313 \mathrm{~K}$ to $553 \mathrm{~K}$.

HPLC-MS analyses were carried out using a Waters HPLC system fitted with reverse phase C18 column $(4.6 \times 17.5 \mathrm{~mm})$ and a UV detector $(\lambda=254 \mathrm{~nm})$ coupled to a ZQ mass spectrometer. The mobile phase was $95 \% \mathrm{H}_{2} \mathrm{O} / 5 \% \mathrm{MeCN}$ changing to $95 \% \mathrm{MeCN}$ and $5 \%$ $\mathrm{H}_{2} \mathrm{O}$ over a 20 min period. The flow rate was set as $1 \mathrm{ml} \mathrm{min}^{-1}$.

\section{Results and discussion}

\section{DFT calculations}

B3LYP calculations aimed at understanding the mechanism of $\mathrm{RuO}_{4}$ oxidation of PAH compounds were carried out using phenanthrene, 1, and pyrene, $\mathbf{2}$, as typical substrates (Figure 1). B3LYP calculated binding energies (Equation (1)) with both phenanthrene and pyrene for coordination of the complex at the symmetry unique $\mathrm{C}=\mathrm{C}$ bond positions are shown in Figure 2. In all cases showing a favourable (negative) binding energy, the singlet state for the $[3+2]$ adduct is found to be at least $10 \mathrm{kcal} \mathrm{mol}^{-1}$ lower in energy than the triplet, and so all studies of reactivity have focused on the singlet potential energy surface as a starting point. We note from Figure $2 a$ that there is clear regioselectivity for the $9,10 \mathrm{C}=\mathrm{C}$ bond in phenanthrene which 
has a binding energy $9.2 \mathrm{kcal} \mathrm{mol}^{-1}$ lower than the next lowest energy site $(3,4)$. Figure $2 b$ also shows that binding of $\mathrm{RuO}_{4}$ to the 9,10 bond in pyrene is also the lowest energy option with a calculated free energy some $15 \mathrm{kcal} \mathrm{mol}^{-1}$ below that of the next most favourable position $(1,2)$. The origin of this effect can be understood in terms of the aromaticity of the ring system: when $\mathrm{RuO}_{4}$ is coordinated; in the [3+2] addition intermediate at the 9,10 positions of phenanthrene or pyrene, aromaticity is only lost in the corresponding ring, while formation of this adduct at any other position results in the loss of aromaticity in at least two rings. The free $\mathrm{RuO}_{4}$ complex is a perfect tetrahedron with calculated $\mathrm{Ru}=\mathrm{O}$ bond lengths of $1.709 \AA$. On coordination to pyrene in the 9,10 position the $\mathrm{Ru}-\mathrm{O}(\mathrm{C})$ bond lengths are notably longer $(1.894 \AA$ and 1.902 $\AA$ ), while the $9,10 \mathrm{C}=\mathrm{C}$ bond length is also increased from $1.362 \AA$ to $1.522 \AA$. These changes are consistent with the formation of the [3+2] adduct being accompanied by reduction of $\mathrm{Ru}$ from the +8 to the +6 oxidation state.

The initial coordination of $\mathrm{RuO}_{4}$ at the 9,10 position is also consistent with the experimentally observed oxidation products previously reported where oxidation was found to give diketones, dialdehydes or acids at these positions both in pyrene and phenanthrene. ${ }^{[16]}$ To see how this $[3+2]$ complex may lead to the observed products we have mapped out the reaction steps for oxidation of the PAHs starting with the [3+2] adduct in the 9,10 positions using the same DFT approach. Scheme 1 shows the mechanistic steps considered in calculations carried out for this work. As we have seen, the formation of the [3+2] adduct, $\mathbf{3}$, leads to a reduction of the $\mathrm{Ru}$ centre from an oxidation state of +8 to +6 . Ring opening at the 9,10 position leads to the dialdehyde, 4, with $\mathrm{Ru}$ reduced to oxidation state +4 in $\mathrm{RuO}_{2}$. Alternatively, $\mathrm{H}$ migration from pyrene to one of the $\mathrm{Ru}$ oxo group oxygen atoms will form a ketone group leading to the monoketone intermediate, $\mathbf{5}$. This intermediate is analogous to the $\mathrm{Ru}$ ester proposed by Bakke and 
Frøhaug who suggested that, for alkane substrates, the ketone can then be transformed into an alcohol by hydrolysis. ${ }^{[13]}$ However, for the present polyaromatic systems, there is the alternative of a second $\mathrm{H}$ abstraction leading to the dione $\mathbf{6}$, which is the experimentally observed major product (Scheme S1-SI).

In both cases, taking this direct route from adduct to dione requires the reduction of the $\mathrm{Ru}$ centre from an oxidation state of +6 to +4 . Figure 3 shows the calculated free energy barriers for either $\mathrm{C}-\mathrm{C}$ bond cleavage or $\mathrm{C}-\mathrm{H}$ activation in the oxidation of pyrene and all calculated data is summarised in Table 1. For the $\mathrm{C}-\mathrm{H}$ activation we consider two possible reaction pathways. In pathway A the $\mathrm{C}-\mathrm{H}$ hydrogen atom is transferred to the nearest $\mathrm{O}$ atom in the five membered ring formed by the [3+2] adduct formation. This leads to a constrained three membered ring transition state which was found to be relatively high in energy $(\Delta \mathrm{G}=58.4 \mathrm{kcal}$ $\left.\mathrm{mol}^{-1}\right)$. As an alternative we also considered the transfer of the $\mathrm{C}-\mathrm{H}$ hydrogen to one of the $\mathrm{Ru}$ oxo oxygen atoms through a folding of the ring which gave a lower barrier by more than 10 $\mathrm{kcal} \mathrm{mol}^{-1}\left(\Delta \mathrm{G}=47.1 \mathrm{kcal} \mathrm{mol}^{-1}\right)$. The lowest barrier identified for oxidation from the $\mathrm{Ru}(+6)$ $[3+2]$ adduct was for C-C cleavage at the 9,10 position with a barrier of $\Delta \mathrm{G}=44.8 \mathrm{kcal} \mathrm{mol}^{-}$ ${ }^{1}$. These results indicate that direct reaction after coordination of $\mathrm{RuO}_{4}$ to the $\mathrm{PAH}$ ring systems would be slow at room temperature.

As mentioned in the Introduction, the reduction potential for $\mathrm{Ru}(+8)$ to $\mathrm{Ru}(+6)$ is considerably greater than that for the transformation of $\mathrm{Ru}(+6)$ to lower oxidation states. Accordingly, we also considered the possibility that, once the [3+2] adduct has formed, the Ru centre is reoxidised to $\mathrm{Ru}(+8)$, by the $\mathrm{NaIO}_{4}$ oxidising agent used in these experiments, before further reaction takes place. In this case the oxidation process may start from a [3+2] adduct with ruthenium in the $\mathrm{Ru}(+8)$ state, 7 , (Scheme 1) rather than 3 . The energetics of the iodate 
oxidation of the [3+2] adduct are difficult to follow using DFT as it will be strongly dependent on solvation of the reactants and transitions state. As a simple check we have calculated the reaction free energy using our standard method for the overall process:

$\mathrm{RuO}_{4} \mathrm{C}_{16} \mathrm{H}_{10}+\mathrm{IO}_{4}^{-}=\mathrm{RuO}_{5} \mathrm{C}_{16} \mathrm{H}_{10}+\mathrm{IO}_{3}^{-}$

where $\mathrm{RuO}_{4} \mathrm{C}_{16} \mathrm{H}_{10}$ is the $\mathrm{Ru}(+6)[3+2]$ adduct of $\mathrm{RuO}_{4}$ with pyrene in the 9,10 position, 3 , and $\mathrm{RuO}_{5} \mathrm{C}_{16} \mathrm{H}_{10}$ is the corresponding structure for $\mathrm{Ru}(+8)$, 7. For the free molecules the reaction free energy for this oxidation process is found to be $29.8 \mathrm{kcal} \mathrm{mol}^{-1}$ and with the addition of polarisable continuum model (PCM) with the dielectric constant of water the reaction energy is found to be $34.0 \mathrm{kcal} \mathrm{mol}^{-1}$. We note that this range of energies is below the barrier calculated for the oxidation reactions to proceed from the $\mathrm{Ru}(+6)[3+2]$ adduct shown in Figure 3 . We also note that $\mathrm{RuO}_{4}$ is formed from $\mathrm{RuCl}_{2}$ by $\mathrm{IO}_{4}{ }^{-}$and so it is reasonable to assume that this oxidation is relatively facile.

From the $\mathrm{Ru}(+8)$ adduct, 7 , the dialdehyde, 4, can be formed by $\mathrm{C}-\mathrm{C}$ bond cleavage in the 5membered metallocycle ring or $\mathrm{H}$ transfer can occur to form a $\mathrm{Ru}$ ester intermediate $\mathbf{8}$, both pathways lead to the reduction of $\mathrm{Ru}(+8)$ to $\mathrm{Ru}(+6)$. This $\mathrm{H}$ abstraction was not considered by Frenking and co-workers who only used ethene as a model substrate. However, they did come to a similar conclusion regarding the requirement that the $\mathrm{Ru}$ centre in the $[3+2]$ intermediate has to be oxidised to $\mathrm{Ru}(+8)$ before $\mathrm{C}-\mathrm{C}$ bond cleavage can take place. ${ }^{[18]}$

Again, for the $\mathrm{C}-\mathrm{H}$ activation step to produce a ketone group, we consider two pathways. Firstly, the transfer of an $\mathrm{H}$ atom to an oxygen in the five membered ring which is directly bonded to the same $\mathrm{C}$ atom. Secondly, $\mathrm{H}$ transfer via a folding of the ring to deliver the $\mathrm{H}$ atom to an oxo group on the Ru centre. Figure 4 shows the calculated transition state geometries for 
these two possibilities as insets on the calculated potential energy surface. Comparing Figures 3 and 4 shows that the calculated barriers for these steps are considerably lower than found when the same transformations take place without first re-oxidising the $\mathrm{Ru}$ ion. We also note that, in the absence of additional solvent molecules in the models, the $\mathrm{C}-\mathrm{C}$ cleavage barrier is lower than that for the $\mathrm{H}$ transfer, $9.3 \mathrm{kcal} \mathrm{mol}^{-1}$ compared to $11.2 \mathrm{kcal} \mathrm{mol}^{-1}$. In addition, we used the transition state for the ring folding to check our assumption that the reaction proceeds on the singlet potential energy surface. This transition state was re-optimised in the triplet state and the electronic energy of the resulting structure was found to be some $5 \mathrm{kcal} \mathrm{mol}^{-1}$ higher in energy than the singlet structure shown in Figure 4. Given the small energy difference calculated between $\mathrm{C}-\mathrm{C}$ and $\mathrm{C}-\mathrm{H}$ bond activation barriers we also carried out single point energy calculations at using the M06 meta-GGA functional at the structures optimised using B3LYP. The M06 calculated free energies gave the same energetic ordering of the calculated barriers with an energy difference of $2.7 \mathrm{kcal} \mathrm{mol}^{-1}$ between the lowest $\mathrm{C}-\mathrm{H}$ activation barrier and that for the C-C cleavage pathway.

The observed difference between the barriers for $\mathrm{C}-\mathrm{C}$ cleavage and $\mathrm{H}$ abstraction would suggest that the major experimental product should be the dialdehyde, 4 . The dialdehyde and its further oxidation products are preferred in biphasic solvents but in monophasic solvent the diketone, $\mathbf{6}$, is more usually observed (Schemes S1 and S4, SI) ${ }^{[16]}$. In the next section we will compare experimental data for pyrene and phenanthrene in monophasic and biphasic solvent systems in more detail and present isotopic labelling studies that give more insight into the mechanism of these reactions.

\section{Oxidation of pyrene and phenathrene using RICO in monophasic solvent}


Analysis by ${ }^{1} \mathrm{H}$ NMR spectroscopy of the products from the pyrene oxidation reaction carried out in the monophasic solvent system showed two major products: pyrene-4,5-dione, $\mathbf{6}$, and pyrene-4,5-dialdehyde, $\mathbf{4}$, as expected from Scheme 1. Similarly, analysis of the oxidation product mixture when using phenanthrene, $\mathbf{1}$, as substrate suggested that the main product, in the monophasic solvent system, is the dione (9,10-phenanthrenequinone, 9) along with a trace amount of biphenyl-2,2'-dicarbaldehyde, $\mathbf{1 0}$ (Scheme S2-SI). ${ }^{[16]}$ These products are consistent with the two primary products expected from the mechanism discussed in the DFT section above. The DFT results suggest that the calculated free energy barrier for $\mathrm{C}-\mathrm{C}$ cleavage in the $[3+2]$ adducts, which leads to the dialdehyde products, was seen to be around $2 \mathrm{kcal} \mathrm{mol}^{-1}$ lower than the $\mathrm{C}-\mathrm{H}$ activation required on the route to dione. This difference is within the accuracy of the DFT methodology used here. We had, therefore expected quite close competition between the reaction pathways leading to dialdehyde or dione in the oxidation of each PAH whereas in monophasic solvents we observe the dione to be the major product. However, the small energy difference in the calculated barriers also suggests that factors not included in the models, such as solvent environment and participation of solvent molecules in the reaction, may be important in determining reaction selectivity. Experimentally we have considered the role of solvent by comparing monophasic and biphasic reactions.

\section{Oxidation of pyrene and phenathrene using RICO in biphasic solvent}

To begin the study of solvent influence on selectivity we compare the product distributions in monophasic and biphasic solvent systems. Reactions for phenanthrene and pyrene oxidation were carried out in the biphasic solvent system $\left(\mathrm{H}_{2} \mathrm{O}(7 \mathrm{ml})\right.$, acetonitrile $(7 \mathrm{ml})$, DCM $\left.(16 \mathrm{ml})\right)$ and detailed product analysis was performed using HPLC-MS. In the case of phenanthrene, two main products were obtained in the organic layer which were identified as 9,10 - 
phenanthrenequinone, 9 and diphenic anhydride, 11. In addition, diphthalic anhydride, 12, was detected in the aqueous layer. (Scheme S3-SI). Diphenic anhydride is a product formed by dehydration of biphenyl-2,2'-dicarboxylic acid, which is the expected final product of phenanthrene oxidation at the 9,10 position. No phenanthrene-4,5-dialdehyde was detected during GC-MS analysis, in agreement with the experiments reported by Kasai et al. ${ }^{[25]}$ This suggests that either the reaction proceeds only via the dione route or that the dialdehyde is rapidly oxidised under our experimental conditions. To distinguish these alternatives, we also considered reactions starting from the 9,10-dione as a reactant.

Scheme 2 summarises the products observed for pyrene oxidation using RICO catalysis in both biphasic and monophasic solvent systems using the DFT calculation results to rationalise the likely order in which each product is produced. Oxidation of pyrene in biphasic solvent resulted in a broader range of products than seen in the monophasic case (Scheme S4-SI) After analysing the reaction mixture using ${ }^{1} \mathrm{H}$ NMR, signals corresponding to pyrene 4,5-dione, $\mathbf{6}$, were identified in the organic layer along with; 9,10-dioxodihydrophenanthrene-4,5dialdehyde, 13, 2',6,6-triformyl-2-carboxylic acid, 14 and the 6,6'-diformylbiphenyl2,2'dicarboxylic acid, 15. In addition, analysis of the aqueous layer shows the presence of the tetra-acid, 16. Based on HPLC-MS analysis the selectivity to pyrene-4,5-dione, 6 , in this reaction was above $90 \%$. This suggests that, although further oxidation to products beyond the dione, 6 , in Scheme 2 do appear, the processes leading to these products are considerably slower than the initial oxidation of the pyrene substrate to the dione, $\mathbf{6}$. This is in agreement with literature reports, where pyrene-4,5-dione is reported as a major product using similar reaction conditions. ${ }^{[26]}$ Our product distributions also indicate that different water 
concentrations in the monophasic and biphasic reactions strongly influence the product distribution and, by inference, the reaction pathway.

\section{Oxidation of pyrene-4,5-dione}

Scheme 2 has assumed, based on our DFT calculations, that the oxidation of pyrene to dione and dialdehyde represent two parallel routes that the reaction can take, rather than sequential oxidation products. Pyrene-4,5-dione, $\mathbf{6}$, is the major product observed from pyrene oxidation in a monophasic solvent system (Scheme S1-SI). The DFT calculations suggest that the initial oxidation, following the formation of the $[3+2]$ adduct, can follow two competitive pathways leading to either dione or dialdehyde, with some kinetic preference for dialdehyde according to the calculated barriers. The oxidation products set out in Scheme 2 and the high selectivity to the dione product in both monophasic and biphasic solvent systems suggest that the aldehyde product leads easily on to higher oxidation products, whereas the dione is a stable, long lived species. To consider this point further we decided to study the oxidation of pyrene-4,5-dione itself in order to get a better understanding of reaction mechanism and test the stability of the dione functional groups under our reaction conditions.

It was found that the reaction, in the monophasic solvent system, resulted in the formation of one major product: pyrene-4,5,9,10-tetraone, 10. It appears, then, that the oxidation of only one ring can take place at any one time and that oxidation of the PAH ring system at the most vulnerable position is preferred over further oxidation of the dione functionality. Therefore, in the case of pyrene-4,5-dione oxidation, we observed products containing two oxygen activated rings, while products derived from the oxidation of pyrene contain only one oxygenated ring. In addition, we also studied the time evolution of tetraone formation and dione consumption as presented in Figure 5. It is clear that pyrene-4,5-dione is directly converted to tetraone with 
selectivity as high as $80 \%$ after $1 \mathrm{hr}$ reaction time. In our discussion of mechanism using DFT calculations we have pointed out that we should expect competitive $\mathrm{C}-\mathrm{H}$ and $\mathrm{C}-\mathrm{C}$ bond cleavage leading to ketones and aldehyde products respectively. However, the solvent environment seems to bias the reaction toward the dione against the expectations of the calculated barriers for the isolated reagents.

In order to study the behaviour of substrates with activated and non-activated aromatic rings, we also perform kinetic studies using pyrene and pyrene 4,5-dione and monitored both product formation and substrate consumption (Figure 6).

It is noteworthy that, as was previously described, pyrene 4,5-dione is the major product of pyrene oxidation, while pyrene tetraone is the major product of pyrene 4,5-dione oxidation. Hence, 4,5-dione only slowly decreases even though the tetraone product is increasing at the same time, which means that the rate of oxidation of pyrene to 4,5-dione and the rate of 4,5dione oxidation to tetraone are roughly the same; so that the ring systems are being oxidised independently of one another. This suggests that $\mathrm{RuO}_{4}$ only attacks one ring at a time and the simultaneous oxidation of 2 rings does not take place in the monophasic solvent system. Also, further oxidation to the diacid is not observed confirming that the dione is a stable product under these conditions.

The differences in product distribution in monophasic and biphasic systems led us to investigate the reaction mechanism with a focus on the involvement of water in key reaction steps. In the monophasic solvent system, water accounts for $33 \%$ of the total volume, suggesting formation of aldehydes. In the biphasic solvent system only $22 \%$ of the solvent is water and so a different product distribution may be expected. Earlier reports have suggested that $\mathrm{C}=\mathrm{C}$ cleavage is involved in the first step of the reaction. ${ }^{[17]}$ However, our own DFT 
calculations point out that initial $\mathrm{C}-\mathrm{H}$ activation can also be a competitive process. The differences in the monophasic and biphasic results highlight that water could play a crucial role in the reaction and so led us to carry out experiments using isotopically labelled water as a component of the solvent system. First, $\mathrm{H}_{2}{ }^{18} \mathrm{O}$ was used in the monophasic solvent system with phenanthrene as a model PAH. There are two reasons for this choice of substrate: Firstly, we avoid solubility problems in the monophasic solvent system and secondly, we reduce the number of products, thereby simplifying the analysis. We also considered deuterium incorporation from $\mathrm{D}_{2} \mathrm{O}$ into the products and performed $\mathrm{KIE}$ studies using $\mathrm{D}_{2} \mathrm{O}$ to identify the involvement of this component of the solvent in the rate determining step for PAH oxidation using RICO chemistry.

\section{Studies using $\mathbf{H}_{2}{ }^{18} \mathrm{O}$}

As mentioned in the experimental section, $\mathrm{H}_{2}{ }^{18} \mathrm{O}$ was used in a scaled down version of our standard reaction conditions with a total solvents volume of $3 \mathrm{ml}$ to reduce the cost of the labelled solvent. Studies using GC-MS showed no difference in product distribution between the normal and the scaled down experiment, which indicated the data from the latter can be used to inform our discussion of the mechanism of PAH oxidation (Figure S2). It has been previously reported that the major product from phenanthrene oxidation is 9,10phenanthrenequinone. ${ }^{[27]}$ Therefore, our studies focused on the formation of this molecule. Based on the MS analysis of this peak from reactions run in both $\mathrm{H}_{2}{ }^{16} \mathrm{O}$ and $\mathrm{H}_{2}{ }^{18} \mathrm{O}$, a difference in the molecular ion peak was observed, which indicates incorporation of ${ }^{18} \mathrm{O}$ into the product. The intensity of peaks $m / z, 182.05$ and $m / z, 212.06$ (Figure $\mathrm{S} 2$ ) suggests that not only ${ }^{18} \mathrm{O}$ is incorporated into products, but also ${ }^{16} \mathrm{O}$ which can come from the $\mathrm{NaIO}_{4}$ oxidant. 
Knowing that peak intensities correspond to concentration of the ionized fragments, we were able to calculate the percentage of 9,10 -phenanthrequinone containing only ${ }^{16} \mathrm{O},{ }^{16} \mathrm{O}$ and ${ }^{18} \mathrm{O}$ or only ${ }^{18} \mathrm{O}$. The peak intensities were as follows: $14.3 \%: 9.6 \%: 76.1 \%$ for $\mathrm{m} / \mathrm{z} 208.0430$, 210.0573 and 212.0606 respectively (Table 2). From this comparison, we can clearly state that most of 9,10-phenanthrenenquinone produced has ketone oxygen atoms derived from $\mathrm{H}_{2}{ }^{18} \mathrm{O}$ $(>76 \%)$.

These results emphasize the role of water in PAH oxidation using RICO chemistry and suggest that the presence of $\mathrm{H}_{2} \mathrm{O}$ is crucial for reaction to occur. However, it is not yet clear that water itself is implicated in the oxygen transfer process between $\mathrm{RuO}_{4}$ and the $\mathrm{PAH}$ substrate. $\mathrm{NaIO}_{4}$ is insoluble in $\mathrm{MeCN}$, so it is understandable that oxygen from water and from sodium periodate will be in equilibrium so that, in $\mathrm{H}_{2}{ }^{18} \mathrm{O}$ enriched solvents, the $\mathrm{RuO}_{4}$ complex will contain a mixture of ${ }^{16} \mathrm{O}$ and ${ }^{18} \mathrm{O}$. Therefore, it is likely that ${ }^{18} \mathrm{O}$ incorporation into reaction products comes from water involved in the $\mathrm{RuO}_{4}$ formation process rather than during the reaction steps involving the $\mathrm{PAH}$ substrate.

\section{Experiments with deuterium labelled water}

The ${ }^{18} \mathrm{O}$ labelling results can be understood via the incorporation of oxygen in the generation of the catalytic $\mathrm{RuO}_{4}$ complex but this does not imply a direct role for water in the oxidation of PAHs. To consider this more closely, $\mathrm{D}_{2} \mathrm{O}$ was included in the reaction mixture.

First, the GC chromatograms from reactions conducted in a monophasic solvent system in both $\mathrm{H}_{2} \mathrm{O}$ and $\mathrm{D}_{2} \mathrm{O}$ were compared. No changes in product distribution were observed for either of the compounds tested. Using GC-MS, each chromatographic peak from the reaction conducted in $\mathrm{H}_{2} \mathrm{O}$ was analyzed by MS and compared with the mass spectra from each peak generated in $\mathrm{D}_{2} \mathrm{O}$. No changes in these were observed when phenanthrene was used as the substrate in 
individual oxidation reactions (Figures S3). Indicating that deuterium was not incorporated into the reaction product in phenanthrene oxidation. Assuming that the oxidation mechanism is the same in monophasic and biphasic solvent systems, no deuterium incorporation should be observed in the products when the reaction is carried out in a $\mathrm{DCM} / \mathrm{MeCN} / \mathrm{D}_{2} \mathrm{O}$ solvent system. However, oxidation of phenanthrene in the biphasic solvent system leads to at least three products: 9,10-phenanthrenequinone 9, phthalic acid detected as diphthalic anhydride, $\mathbf{1 2}$ and diphenic acid detected as its diphenic anhydride, $11 .{ }^{[25,28]}$ The presence of acids already suggests that oxidation proceeds further in the biphasic solvent than in the monophasic system. This is likely related to the solubility of the oxidation products in the aqueous layer. To confirm this, the GC chromatograms from oxidation of phenanthrene run in $\mathrm{DCM} / \mathrm{MeCN} / \mathrm{H}_{2} \mathrm{O}$, $\mathrm{DCM} / \mathrm{MeCN} / \mathrm{H}_{2} \mathrm{O} / \mathrm{D}_{2} \mathrm{O}$ mixture and $\mathrm{DCM} / \mathrm{MeCN} / \mathrm{D}_{2} \mathrm{O}$ were compared. GC chromatograms and mass spectra for product found in the organic layer showed no changes in product distribution between reactions with different water composition. Using GC-MS, each chromatogram peak from the reaction run in $\mathrm{DCM} / \mathrm{MeCN} / \mathrm{H}_{2} \mathrm{O}$ was analyzed by $\mathrm{MS}$ and compared with the MS of products for the reaction conducted in $\mathrm{DCM} / \mathrm{MeCN} / \mathrm{D}_{2} \mathrm{O}$. No change in the mass distribution was observed in either layer (Diphenic anhydride shown as an example: Figure S4). These findings indicate that, as expected for this oxidation, H/D from water is not incorporated into products; however, water may still be involved in the reaction mechanism. In order to answer this question, we observed the conversion of pyrene as a function of time in $\mathrm{H}_{2} \mathrm{O}$ and $\mathrm{D}_{2} \mathrm{O}$ containing solvents so that the magnitude of any KIE could be estimated.

\section{Kinetic Studies using $\mathrm{D}_{2} \mathrm{O}$ and $\mathrm{H}_{2} \mathrm{O}$}

After performing reactions in the presence of $\mathrm{H}_{2} \mathrm{O}$ or $\mathrm{D}_{2} \mathrm{O}$, we compared the rate of phenanthrene consumed during the reaction and expressed it as a kinetic isotope effect (KIE). 
The calculated KIE value for these reactions was $k_{H} / k_{D}=1.71$, which suggests a primary kinetic isotope effect and the involvement of water in the rate determining step.

We have suggested that the reaction mechanism is independent of the solvent system used, therefore kinetic studies using $\mathrm{H}_{2} \mathrm{O}$ and $\mathrm{D}_{2} \mathrm{O}$ were also performed in a biphasic solvent system with phenanthrene as substrate. Figure 7 compares the consumption of phenanthrene in the reaction performed in the presence of $\mathrm{H}_{2} \mathrm{O}$ and $\mathrm{D}_{2} \mathrm{O}$. Here, the calculated KIE value for phenanthrene oxidation was found to be $k_{H} / k_{D}=1.54$ which is also consistent with a primary kinetic isotope effect. Taking into account the fact that in both solvent systems no deuterium incorporation into the products was observed during phenanthrene oxidation, we assume that the mechanism of the reaction is the same in the monophasic and in biphasic solvent systems and therefore similar KIE value should be observed.

Summarizing all the information obtained from mechanistic investigations it is clear that water is involved in the rate determining step. Hydrogen from water is not incorporated into the products whereas oxygen is incorporated from this source but probably during the formation of the $\mathrm{RuO}_{4}$ oxidising species.

To look at a possible origin of the kinetic isotope effect, further DFT calculations were undertaken. In these calculations two water molecules were added to the $[3+2]$ intermediate for pyrene with $\mathrm{Ru}$ in the +8 oxidation state, $3 \mathbf{a}$. These were placed to hydrogen bond to the oxygen atoms of the complex and to each other. We then used a combination of coordinate scans, transition state optimisation and frequency calculations to obtain transition states for the C-C cleavage and $\mathrm{H}$ abstraction pathways with the water molecules present. The resulting structures are shown in Figure 8. In this case a transition state has been found in which the $\mathrm{H}$ atom 
abstracted during the formation of a ketone group is received by a water molecule, Figure $8 \mathrm{a}$. This sets off a proton-shuttle resulting in the formation of the ketone group and protonation of one of the oxygen atoms coordinated to $\mathrm{Ru}$. The rate following this type of mechanism would clearly be affected by H/D exchange. However, the calculated barrier in this case is higher (by some $7.3 \mathrm{kcal} \mathrm{mol}^{-1}$ ) than seen in Figure 4 for the corresponding step without solvent present in the model. We expect that the low energy pathway observed in the absence of solvent in which the five membered ring "folds" to transfer the $\mathrm{H}$ atom to an $\mathrm{Ru}=\mathrm{O}$ oxygen atom may actually be hindered in the presence of solvent. However, when a model was constructed to test this by placing a water molecule between the $\mathrm{H}$ atom and the receiving oxygen atom no transition state could be located. For the C-C cleavage pathway Figure $8 \mathrm{~b}$ shows that the calculated barrier was also increased by the inclusion of water molecules in the calculation, from $9.3 \mathrm{kcal} \mathrm{mol}^{-1}$ (Figure 4) to $15.1 \mathrm{kcal} \mathrm{mol}^{-1}$. This is probably because of the rearrangement of the water hydrogen bonding pattern that must accompany the $\mathrm{C}-\mathrm{C}$ bond cleavage. Even so, the barrier to C-C bond cleavage which leads to the dialdehyde product remains $3.4 \mathrm{kcal} \mathrm{mol}^{-1}$ below that for $\mathrm{H}$ abstraction. The inclusion of the water molecules increases considerably the configuration space for these calculations and so further work is underway to look at the effect of the number and arrangement of solvent molecules and continuum representations of solvent. We may expect that improved solvation models should identify lower energy pathways. Even so the current calculations provide insight into the likely origin of the experimentally observed kinetic isotope effect.

\section{Conclusions}

Studies related to mechanistic investigation helped to reveal and understand the chemistry of aromatic $\mathrm{C}=\mathrm{C}$ bond cleavage. $\mathrm{DFT}$ calculations suggested that the $[3+2]$ complex formation at 
the 9,10 position on phenanthrene or pyrene can explain the observed regioselectivity in terms of preserving the aromaticity of the substrate. For oxidation of pyrene starting from this adduct there is a branching of the pathway to either form diketones or dialdehydes, the latter being further oxidised to diacids. DFT calculations suggest that the $\mathrm{Ru}$ centre is first oxidised to $\mathrm{Ru}(+8)$ before oxidation of the substrate takes place. Once this has occurred, reaction to ketone or aldehyde occurs via barriers that are within $2 \mathrm{kcal} \mathrm{mol}^{-1}$ of one another so that the selectivity is difficult to predict from calculations alone. Experimentally the product distribution is strongly affected by the solvent choice with the diketone seen to be dominant when monophasic solvents are used but the dialdehyde and its oxidation products are preferred in biphasic solvents, in which the reaction mixture contains less water. This suggests that the balance between the two pathways identified by the DFT calculations can be influenced by factors not included in the model, such as the solvent choice, because the calculated barriers are the same within the limits of accuracy expected from the DFT method.

Radio labelling experiments also shows the importance of water in the rate determining step of the diketone formation. Studies with $\mathrm{H}_{2}{ }^{18} \mathrm{O}$ showed incorporation of ${ }^{18} \mathrm{O}$ into reaction products, emphasizing the role of water. From experiments with $\mathrm{D}_{2} \mathrm{O}$, we observe a KIE for phenanthrene and further DFT calculations show how this may be explained by a proton shuttle style mechanism for the abstraction of the first $\mathrm{H}$ atom from the PAH.

\section{Acknowledgements}

We would like to thank the Exxon Mobil Corporation for studentships for EN and NMH. EN thanks TU Berlin for awarding her IPODI fellowship. Via our membership of the UK's HPC Materials Chemistry Consortium, which is funded by EPSRC (EP/L000202), this work made use of the facilities of HECToR and ARCHER. Computing resource was also provided by 
Advanced Research Computing at Cardiff (ARCCA) and the HPC-Wales supercomputer facilities.

The data used to produce the results presented in this paper can be found at: http://doi.org/10.17035/d.2018.0045182615 


\section{Captions for Figures}

Figure 1. Structure of phenanthrene and pyrene showing standard atom numbering scheme.

Figure 2. The calculated binding free energies for $\mathrm{RuO}_{4}$ forming a [3+2] adduct at each symmetry unique $\mathrm{C}=\mathrm{C}$ bond in $a$ ) phenanthrene, $\mathbf{1}$ and $b$ ) pyrene, $\mathbf{2}$. Solid lines are for calculations in the singlet and dashed lines calculations for the triplet spin states of the complexes. Model inset in $(b)$ shows the calculated structure of the $[3+2]$ adduct at the $(9,10)$ position with atoms show in ball representation coloured $\mathrm{Ru}$ : green, O: red, C: grey and $\mathrm{H}$ : white, pyrene atoms not part of the five membered metallocycle ring are coloured light grey and drawn as sticks only.

Figure 3. Calculated reaction barriers for $\mathrm{C}-\mathrm{C}$ and $\mathrm{C}-\mathrm{H}$ activation of the $[3+2]$ adduct formed between $\mathrm{RuO}_{4}$ and pyrene at the $(9,10)$ position calculated with the $\mathrm{Ru}(+6)$ adduct as starting point. Inset graphics have atoms show in ball representation coloured Ru: green, O: red, C: grey and $\mathrm{H}$ : white, pyrene atoms not part of the five membered metallocycle ring are coloured light grey and drawn as sticks only.

Figure 4. Calculated reaction barriers for $\mathrm{C}-\mathrm{C}$ and $\mathrm{C}-\mathrm{H}$ activation of the $[3+2]$ adduct formed between $\mathrm{RuO}_{4}$ and pyrene at the $(9,10)$ position calculated starting with a $\mathrm{Ru}(+8)$ adduct. Atom representations as described for Figure 3.

Figure 5. Pyrene-4,5-dione ( $\square$ ) oxidation and pyrene-4,5,9,10-tetraone ( $\square$ ) formation. Reaction Conditions: Pyrene 4,5-dione 0.0349 mmol, $\mathrm{NaIO}_{4} 0.174 \mathrm{mmol}, \mathrm{RuCl}_{3} 0.0002 \mathrm{mmol}$, $\mathrm{MeCN} 20 \mathrm{ml}, \mathrm{H}_{2} \mathrm{O} 10 \mathrm{ml}$ (i.e. monophasic), T=295 K, Stirring speed $500 \mathrm{rpm}$.

Figure 6. Competitive oxidation of pyrene (•) and pyrene-4,5-dione (•) Pyrene-4,5,9,10tetraone $(\square)$ also marked on the graph as a product.

Reaction Conditions: Substrate $0.0349 \mathrm{mmol}, \mathrm{NaIO}_{4} 0.554 \mathrm{mmol}, \mathrm{RuCl}_{3} 0.0006 \mathrm{mmol}, \mathrm{MeCN}$ $40 \mathrm{ml}, \mathrm{H}_{2} \mathrm{O} 20 \mathrm{ml}$, (i.e. monophasic), T=295 K, Stirring speed $500 \mathrm{rpm}$.

Figure 7. Kinetic isotope effect experiments for the oxidation of phenanthrene a) with monophasic solvent composition: $\mathrm{MeCN} 20 \mathrm{ml}, \mathrm{D}_{2} \mathrm{O}(\Delta) / \mathrm{H}_{2} \mathrm{O}(\boldsymbol{\Delta}) 10 \mathrm{ml}$ and b) using biphasic solvent system composition: $\mathrm{H}_{2} \mathrm{O}(\boldsymbol{\Delta}) / \mathrm{D}_{2} \mathrm{O}(\Delta) 7 \mathrm{ml}$, DCM $16 \mathrm{ml}$, MeCN $7 \mathrm{ml}$.

Figure 8. Calculated transition state structures for $a$ ) $\mathrm{C}-\mathrm{H}$ and $b$ ) $\mathrm{C}-\mathrm{C}$ activation of the [3+2] adduct formed between $\mathrm{RuO}_{4}$ and pyrene at the $(9,10)$ position calculated starting with a $\mathrm{Ru}(+8)$ adduct including two water molecules. The values refer to the calculated free energy for the barrier to reaction along the respective pathways ( $\mathrm{kcal} \mathrm{mol}^{-1}$ units). Atom representations as described for Figure 3. 

Figure 1. Structures of $a$ ) phenanthrene and $b$ ) pyrene showing standard atom numbering scheme.

a)

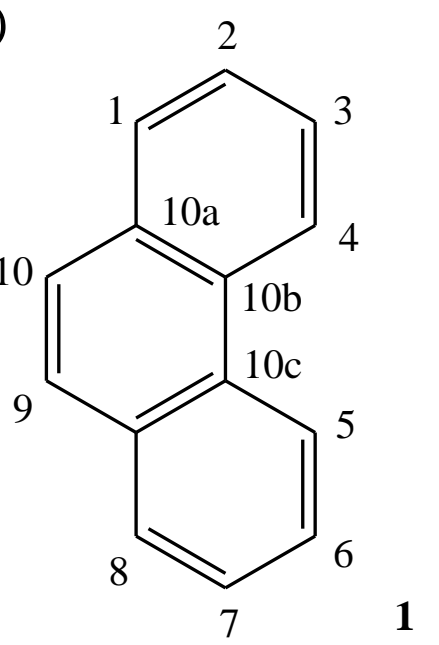

b)

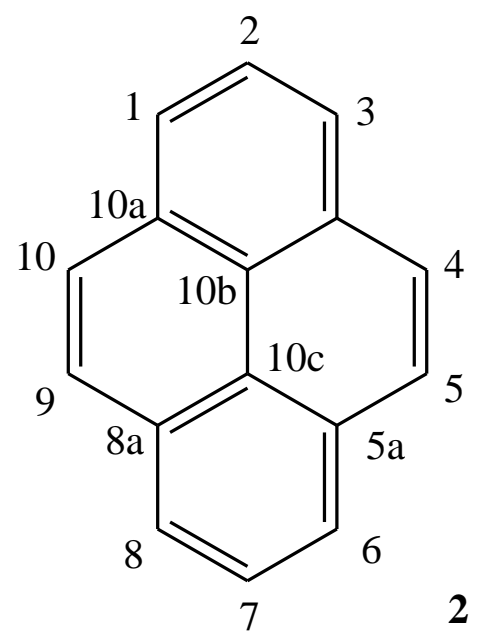


Figure 2. The calculated binding free energies for $\mathrm{RuO}_{4}$ forming a [3+2] adduct at each symmetry unique $\mathrm{C}=\mathrm{C}$ bond in $a$ ) phenanthrene, $\mathbf{1}$ and $b$ ) pyrene, $\mathbf{2}$. Solid lines are for calculations in the singlet and dashed lines calculations for the triplet spin states of the complexes. Model inset in $(b)$ shows the calculated structure of the $[3+2]$ adduct at the $(9,10)$ position with atoms show in ball representation coloured $\mathrm{Ru}$ : green, $\mathrm{O}$ : red, $\mathrm{C}$ : grey and $\mathrm{H}$ : white, pyrene atoms not part of the five membered metallocycle ring are coloured light grey and drawn as sticks only.
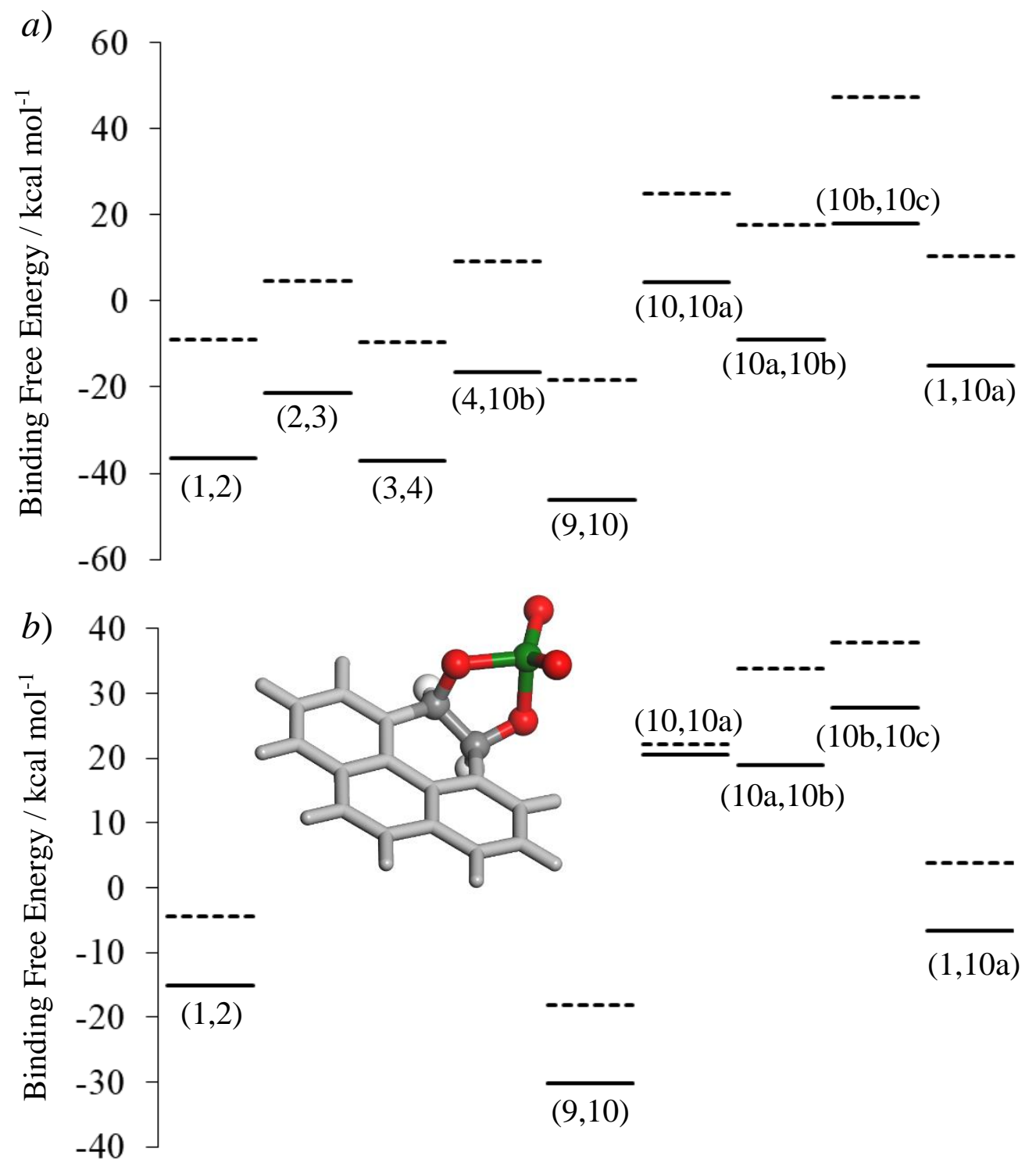
Figure 3. Calculated reaction barriers for $\mathrm{C}-\mathrm{C}$ and $\mathrm{C}-\mathrm{H}$ activation of the $[3+2]$ adduct formed between $\mathrm{RuO}_{4}$ and pyrene at the $(9,10)$ position calculated with the $\mathrm{Ru}(+6)$ adduct as starting point. Inset graphics have atoms show in ball representation coloured $\mathrm{Ru}$ : green, $\mathrm{O}$ : red, $\mathrm{C}$ : grey and $\mathrm{H}$ : white, pyrene atoms not part of the five membered metallocycle ring are coloured light grey and drawn as sticks only.

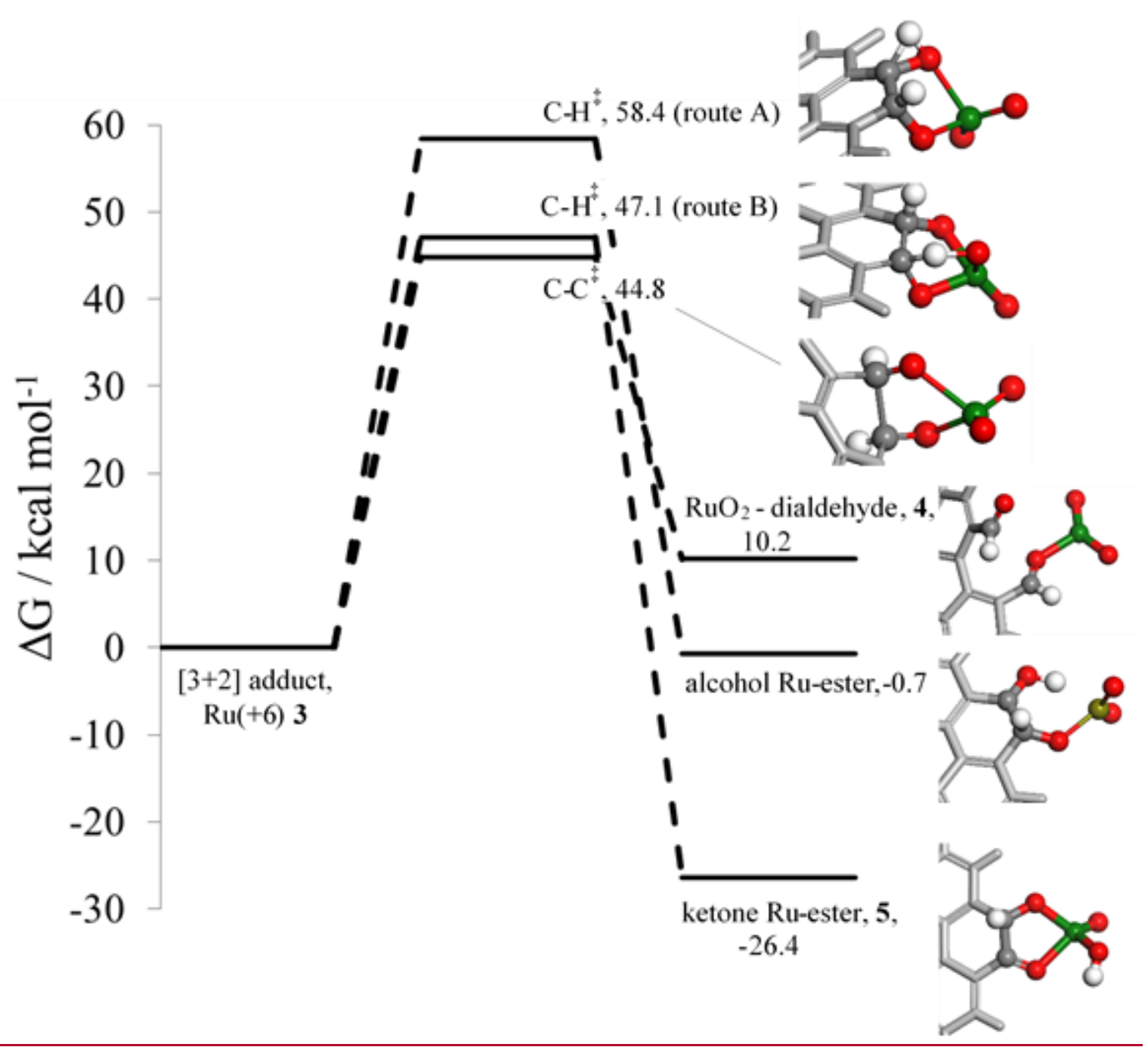


Figure 4. Calculated reaction barriers for $\mathrm{C}-\mathrm{C}$ and $\mathrm{C}-\mathrm{H}$ activation of the $[3+2]$ adduct formed between $\mathrm{RuO}_{4}$ and pyrene at the $(9,10)$ position calculated starting with a $\mathrm{Ru}(+8)$ adduct. Atom representations as described for Figure 3.
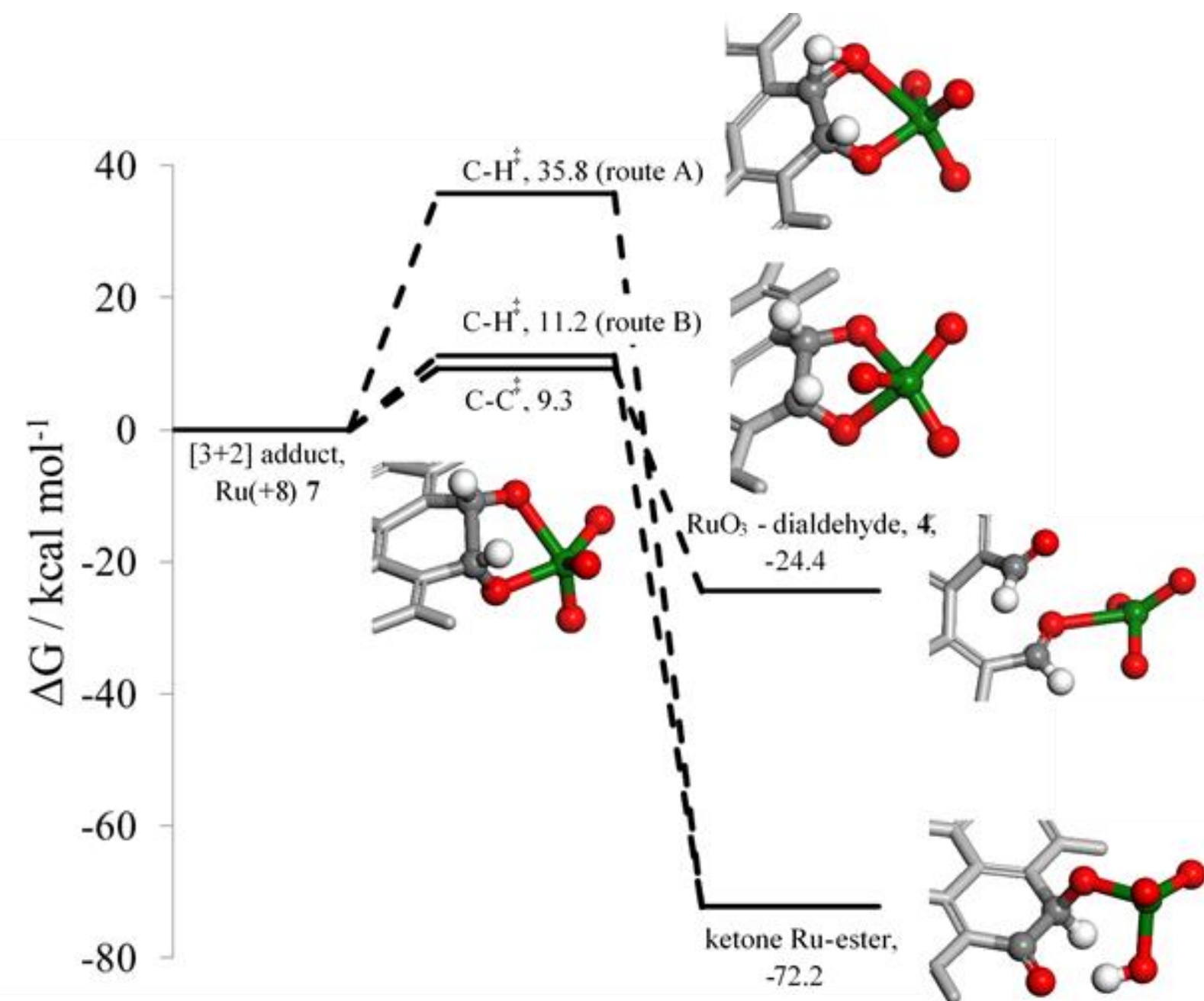
$-72.2$

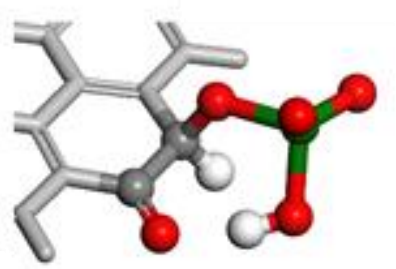


Figure 5. Pyrene-4,5-dione ( $\bullet$ ) oxidation and pyrene-4,5,9,10-tetraone ( $\square$ ) formation Reaction Conditions: Pyrene 4,5-dione $0.0349 \mathrm{mmol}, \mathrm{NaIO}_{4} 0.174 \mathrm{mmol}, \mathrm{RuCl}_{3} 0.0002 \mathrm{mmol}$, $\mathrm{MeCN} 20 \mathrm{ml}, \mathrm{H}_{2} \mathrm{O} 10 \mathrm{ml}$, (i.e. monophasic), T=295 K, Stirring speed $500 \mathrm{rpm}$.

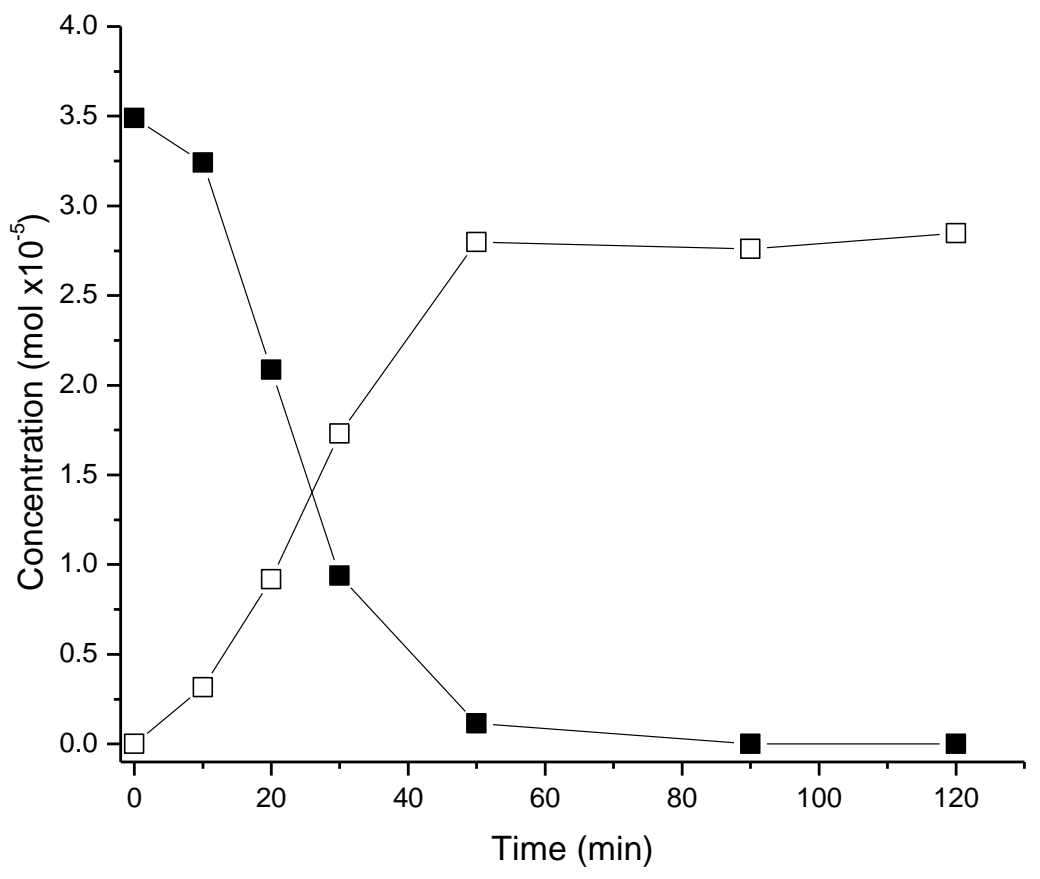




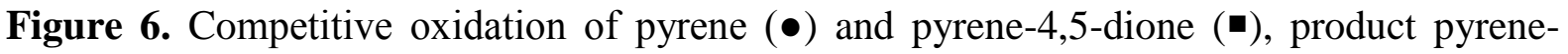
4,5,9,10-tetraone ( $\square$ ).

Reaction Conditions: Substrate $0.0349 \mathrm{mmol}, \mathrm{NaIO}_{4} 0.554 \mathrm{mmol}, \mathrm{RuCl}_{3} 0.0006 \mathrm{mmol}, \mathrm{MeCN}$ $40 \mathrm{ml}, \mathrm{H}_{2} \mathrm{O} 20 \mathrm{ml}$, (i.e. monophasic), T=295 K, Stirring speed $500 \mathrm{rpm}$.

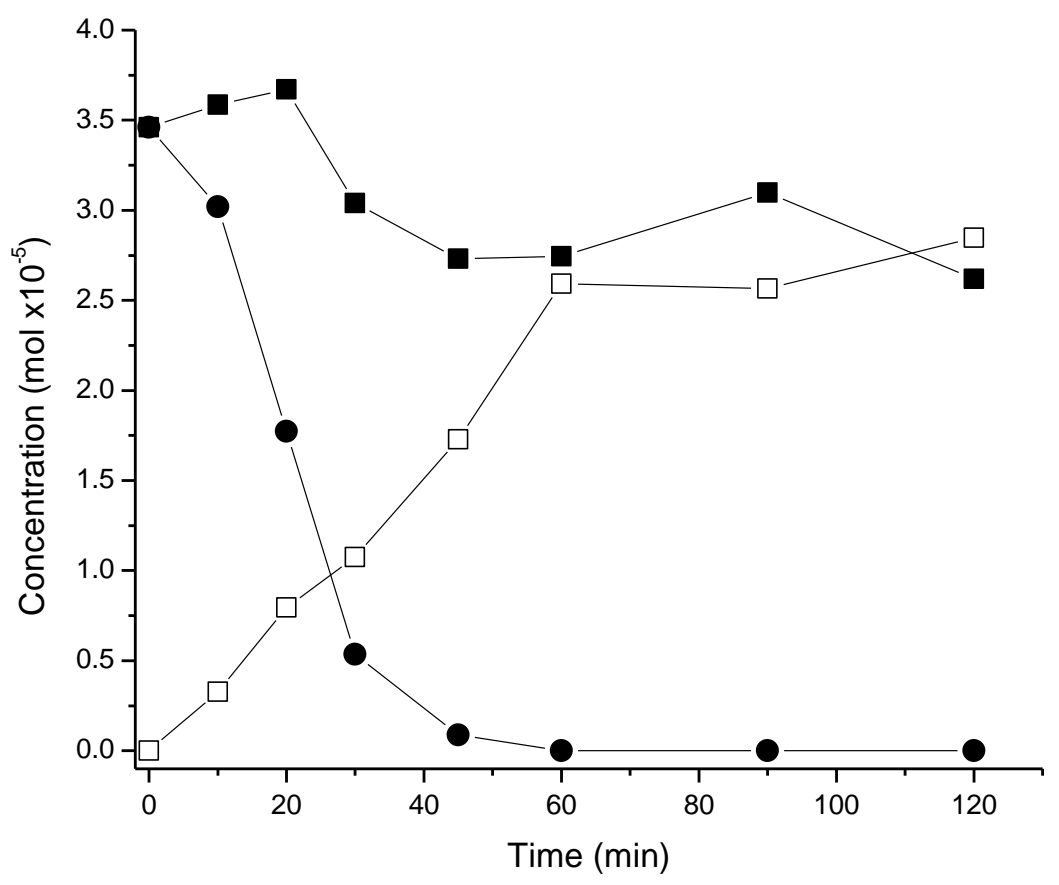


Figure 7. Kinetic isotope effect experiments for the oxidation of phenanthrene $a$ ) with monophasic solvent composition: $\mathrm{MeCN} 20 \mathrm{ml}, \mathrm{D}_{2} \mathrm{O}(\Delta) / \mathrm{H}_{2} \mathrm{O}(\boldsymbol{\Delta}) 10 \mathrm{ml}$ and $b$ ) using biphasic solvent system composition: $\mathrm{H}_{2} \mathrm{O}(\boldsymbol{\Delta}) / \mathrm{D}_{2} \mathrm{O}(\Delta) 7 \mathrm{ml}$, DCM $16 \mathrm{ml}$, MeCN $7 \mathrm{ml}$.
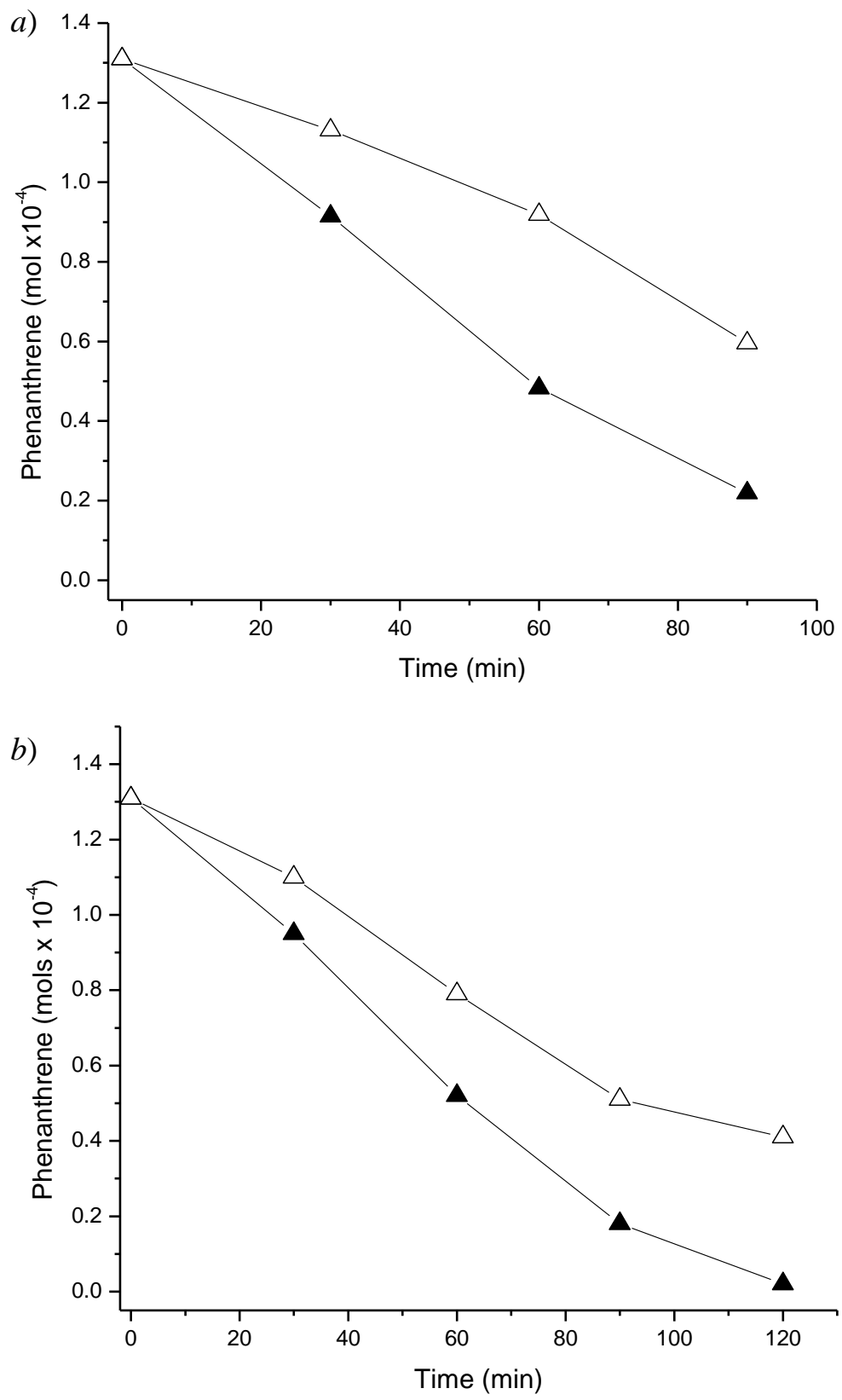
Figure 8. Calculated transition state structures for $a$ ) $\mathrm{C}-\mathrm{H}$ and $b$ ) $\mathrm{C}-\mathrm{C}$ activation of the [3+2] adduct formed between $\mathrm{RuO}_{4}$ and pyrene at the $(9,10)$ position calculated starting with a $\mathrm{Ru}(+8)$ adduct including two water molecules. The values refer to the calculated free energy for the barrier to reaction along the respective pathways ( $\mathrm{kcal} \mathrm{mol}^{-1} \mathrm{units}$ ). Atom representations as described for Figure 3.

a)

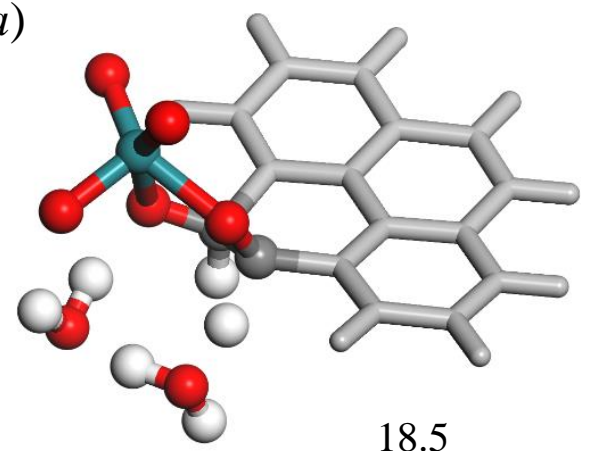

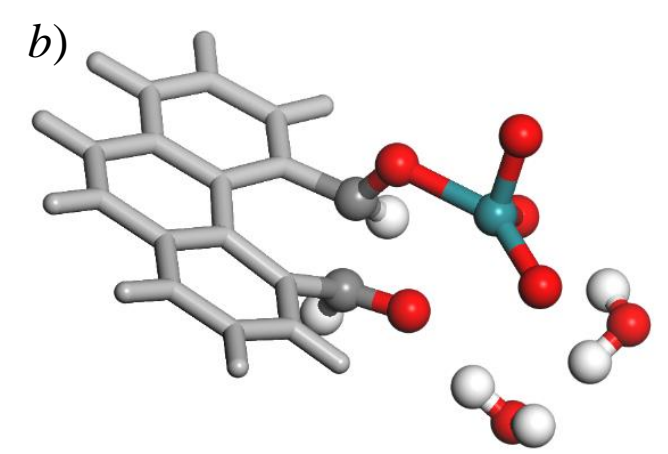

15.1 


\section{Captions for Tables}

Table 1. Calculated energetics for pyrene oxidation using $\mathrm{RuO}_{4}$.

Table 2. Comparison of selectivity in phenanthrene oxidation under different conditions in monophasic solvent system. 
Table 1. Calculated energetics for pyrene oxidation using $\mathrm{RuO}_{4}$.

\begin{tabular}{|c|c|c|}
\hline & \multicolumn{2}{|c|}{ B3LYPa } \\
\hline & $\begin{array}{c}\Delta E^{b} \\
/ \mathrm{kcal} \mathrm{mol}^{-1}\end{array}$ & $\begin{array}{c}\Delta G^{c} \\
/ \mathrm{kcal} \mathrm{mol}^{-1}\end{array}$ \\
\hline \multicolumn{3}{|l|}{ Pyrene (Ru(VI)) } \\
\hline$[3+2]-\mathbf{4}, \mathrm{TS}$ & 48.8 & 44.8 \\
\hline $\mathrm{RuO}_{2}$-dialdehyde, 4 & 16.2 & 10.2 \\
\hline$[3+2]-\mathbf{5}, \mathrm{TS}(\mathrm{A})^{\mathrm{d}}$ & 64.0 & 58.4 \\
\hline$[3+2]-\mathbf{5}, \mathrm{TS}(\mathrm{B})^{\mathrm{e}}$ & 51.3 & 47.1 \\
\hline alcohol Ru-ester & 3.4 & -0.7 \\
\hline \multicolumn{3}{|l|}{ Pyrene (Ru(VIII)) } \\
\hline$[3+2]-\mathbf{4}, \mathrm{TS}$ & 9.8 & 9.3 \\
\hline $\mathrm{RuO}_{3}$-dialdehyde, 4 & -20.8 & -24.4 \\
\hline$[3+2]-\mathbf{8}, \mathrm{TS}(\mathrm{A})^{\mathrm{d}}$ & 36.4 & 35.8 \\
\hline$[3+2]-\mathbf{8}, \mathrm{TS}(\mathrm{B})^{\mathrm{e}}$ & 10.6 & 11.2 \\
\hline ketone Ru-ester, 8 & -71.0 & -72.2 \\
\hline
\end{tabular}

Notes: a) B3LYP/6-31G(d,p)/LANL2DZ, b) calculated energy difference including ZPE, c) calculated free energy difference based on ZPE correction and standard thermochemistry at T=298 K. d) C-H activation to O in five membered ring, figure 4, route $\mathrm{A}$, e) $\mathrm{C}-\mathrm{H}$ activation to $\mathrm{Ru}$ oxo $\mathrm{O}$ via ring folding, figure 4, route $\mathrm{B}$. 
Table 2. Comparison of selectivity in phenanthrene oxidation under different conditions in monophasic solvent system.

\begin{tabular}{|c|c|c|c|}
\hline \multirow[t]{2}{*}{ Reaction } & \multicolumn{3}{|c|}{ Product Selectivity (\%) } \\
\hline & $\begin{array}{c}\text { Phenanthrene } \\
\text { 9,10-dione }\end{array}$ & $\begin{array}{c}\text { Phenanthrene } \\
9,10 \text {-dialdehyde }\end{array}$ & Other \\
\hline $\begin{array}{l}\text { Standard Reaction }^{a} \\
\text { with } 10 \mathrm{ml} \mathrm{H}_{2} \mathrm{O}\end{array}$ & 87 & 9 & 4 \\
\hline 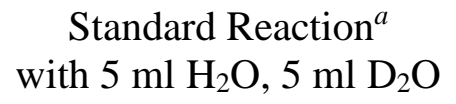 & 85 & 8 & 7 \\
\hline $\begin{array}{l}\text { Standard Reaction }^{a} \\
\text { with } 10 \mathrm{ml} \mathrm{D}_{2} \mathrm{O}\end{array}$ & 84 & 9 & 7 \\
\hline $\begin{array}{l}\text { Scale down reaction } \\
\text { with } 1 \mathrm{ml} \mathrm{H}_{2} \mathrm{O}\end{array}$ & 88 & 10 & 2 \\
\hline $\begin{array}{l}\text { Scale down reaction } \\
\text { with } 1 \mathrm{ml} \mathrm{H}_{2}{ }^{18} \mathrm{O}\end{array}$ & 87 & 7 & 6 \\
\hline
\end{tabular}




\section{Captions for Schemes}

Scheme 1. Representations of mechanistic steps considered during oxidation of pyrene to pyrene 4, 5-dione.

Scheme 2. Pyrene Oxidation: Sequence of oxidation based on ${ }^{1} \mathrm{H}-\mathrm{NMR}$ of monophasic, HPLC-MS analysis of biphasic reaction and DFT calculations.

Reaction Conditions: Pyrene $0.131 \mathrm{mmol}^{\mathrm{NaIO}} \mathrm{N}_{4} 1.048 \mathrm{mmol}, \mathrm{RuCl}_{3} 0.01 \mathrm{mmol}, \mathrm{DCM} 16 \mathrm{ml}$, $\mathrm{MeCN} 7 \mathrm{ml}, \mathrm{H}_{2} \mathrm{O} 7 \mathrm{ml}, \mathrm{T}=295 \mathrm{~K}$, Stirring speed $500 \mathrm{rpm}, \mathrm{t}=4 \mathrm{~h}$. mono. indicates product seen in monophasic reaction, org./aq./not seen indicate product found in organic/aqueous layer or not detected in biphasic reaction $(T=308 \mathrm{~K})$ respectively. 


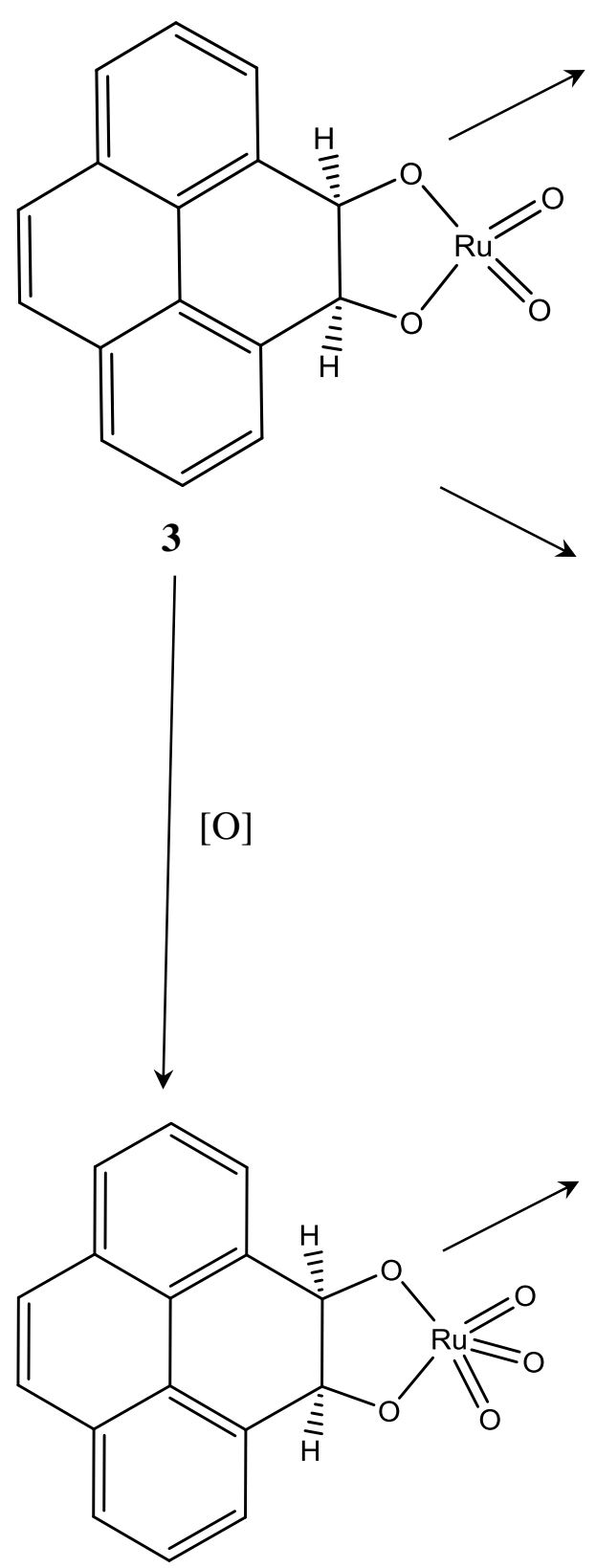

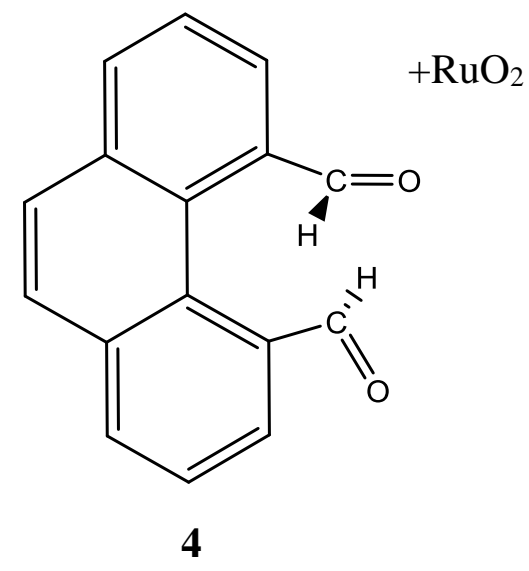

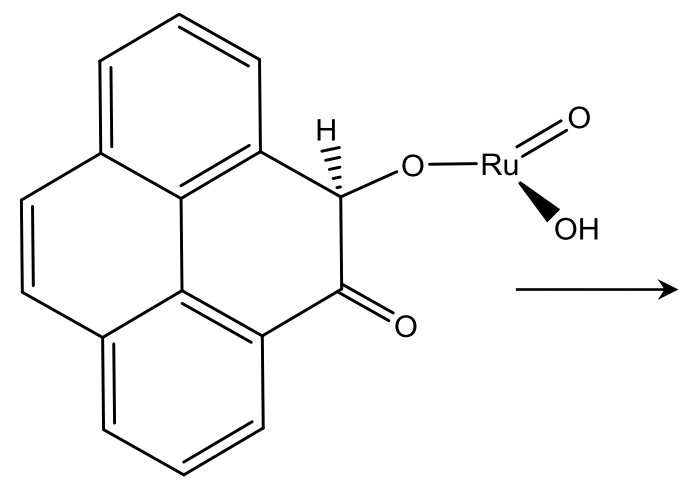

5

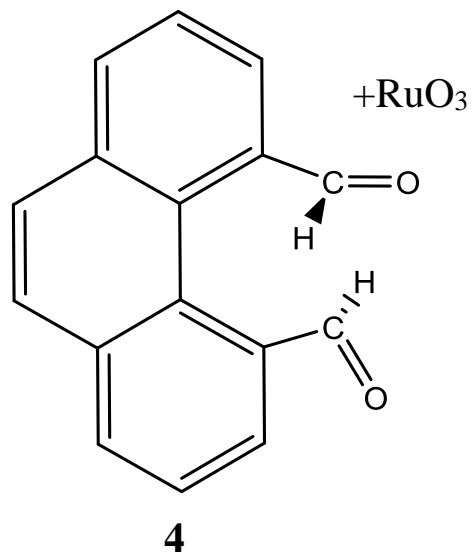
pyrene 4, 5-dione.
6<smiles>O=c1c(=O)c2cccc3ccc4cccc1c4c32</smiles>

7

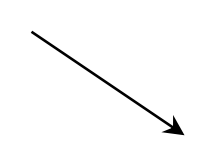<smiles>[H][R4](=O)(O)O[C@H]1C(=O)c2cccc3ccc4cccc1c4c23</smiles>

Scheme 1. Representations of mechanistic steps considered during oxidation of pyrene to

$+\mathrm{RuO}(\mathrm{OH})_{2}$

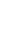


Scheme 2. Pyrene Oxidation: Sequence of oxidation based on ${ }^{1} \mathrm{H}-\mathrm{NMR}$ of monophasic, HPLC-MS analysis of biphasic reaction and DFT calculations.

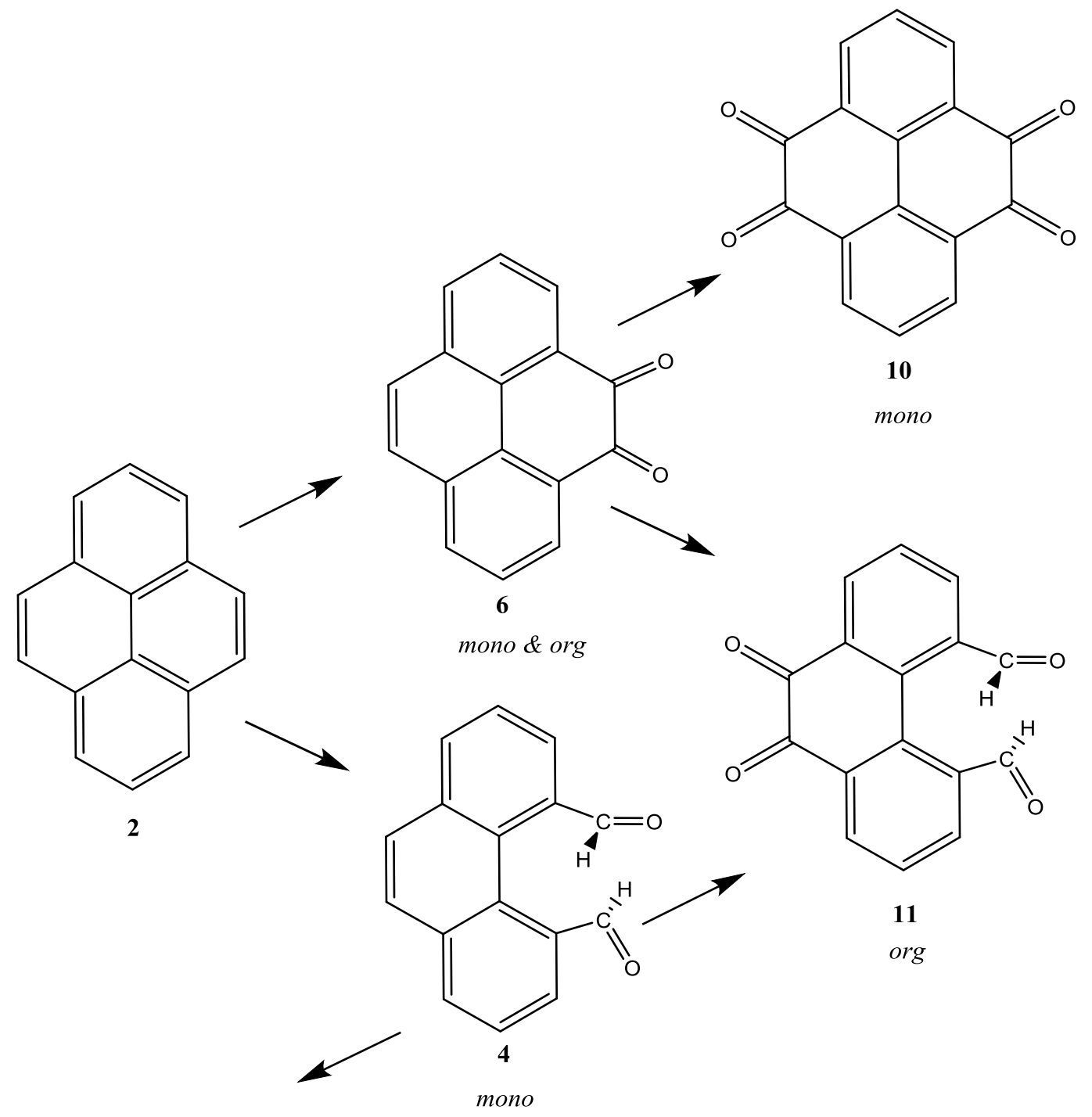<smiles>O=Cc1cccc(C=O)c1-c1c(C=O)cccc1C(=O)O</smiles>

12

org<smiles>O=[13CH]c1c(C(=O)O)cccc1C(=O)O</smiles> 


\section{References}

[1] C. Djerassi, R. R. Engle, J. Am. Chem. Soc. 1953, 75, 3838-3840.

[2] A. Mills, C. Holland, J. Chem. Res-S. 1997, 368-369.

[3] P. H. J. Carlsen, T. Katsuki, V. S. Martin, K. B. Sharpless, J. Org. Chem. 1981, 46, 39363938.

[4] a) V. Piccialli, D. M. A. Smaldone, D. Sica, Tetrahedron 1993, 49, 4211-4228; b) T. K. M. Shing, E. K. W. Tam, V. W. F. Tai, I. H. F. Chung, Q. Jiang, Chem. Eur. J. 1996, 2, 50-57; c) T. K. M. Shing, V. W. F. Tai, E. K. W. Tam, Angew. Chem. Int. Edit. 1994, 33, 2312-2313.

[5] a) H. Yamaoka, N. Moriya, M. Ikunaka, Org. Process Res. Dev. 2004, 8, 931-938; b) A. M. Felix, J. V. Earley, R. I. Fryer, L. H. Sternbach, J. Heterocycl. Chem. 1968, 5, 731.

[6] a) K. Morikawa, J. Park, P. G. Andersson, T. Hashiyama, K. B. Sharpless, J. Am. Chem. Soc. 1993, 115, 8463-8464; b) N. Momiyama, H. Yamamoto, J. Am. Chem. Soc. 2003, 125, 60386039 .

[7] a) B. Plietker, Eur. J. Org. Chem. 2005, 1919-1929; b) B. Plietker, J. Org. Chem. 2004, 69, 8287-8296.

[8] a) G. Bifulco, T. Caserta, L. Gomez-Paloma, V. Piccialli, Tetrahedron Lett. 2002, 43, 92659269; b) G. Bifulco, T. Caserta, L. Gomez-Paloma, V. Piccialli, Tetrahedron Lett. 2003, 44, 5499-5503.

[9] a) D. Yang, C. Zhang, J. Org. Chem. 2001, 66, 4814-4818; b) D. Yang, F. Chen, Z. M. Dong, D. W. Zhang, J. Org. Chem. 2004, 69, 2221-2223.

[10] a) H. Petride, C. Drãghici, C. Florea, A. Petride, Cent. Eur. J. Chem.2004, 2, 302-322; b) H. Petride, O. Costan, C. Drăghici, C. Florea, A. Petride, Arkivoc 2005, 2005, 18-32; c) R. S. Glass, J. L. Broeker, Tetrahedron 1991, 47, 5077-5086; d) W. Su, Tetrahedron Lett. 1994, 35 , 4955-4958.

[11] a) D. M. Piatak, G. Herbst, J. Wicha, E. Caspi, J. Org. Chem. 1969, 34, 116-120; b) S. Imajo, H. Kuritani, K. Shingu, M. Nakagawa, J. Org. Chem. 1979, 44, 3587-3589; c) J. Hu, D. Zhang, F. W. Harris, J. Org. Chem. 2005, 70, 707-708.

[12] M. Pagliaro, S. Campestrini, R. Ciriminna, Chem. Soc. Rev. 2005, 34, 837-845.

[13] J. M. Bakke, A. E. Frøhaug, J. Phys. Org. Chem. 1996, 9, 310-318.

[14] a) A. Ma, S. Zhang, D. Zhang, Org. Geochem. 2008, 39, 1502-1511; b) Y.-G. Huang, Z.-M. Zong, Z.-S. Yao, Y.-X. Zheng, J. Mou, G.-F. Liu, J.-P. Cao, M.-J. Ding, K.-Y. Cai, F. Wang, W. Zhao, Z.-L. Xia, L. Wu, X.-Y. Wei, Energy \& Fuels 2008, 22, 1799-1806; c) S. Murata, K. U-esaka, H. Ino-ue, M. Nomura, Energy \& Fuels 1994, 8, 1379-1383; d) F.-J. Liu, X.-Y. Wei, J. Gui, P. Li, Y.-G. Wang, W.-T. Li, Z.-M. Zong, X. Fan, Y.-P. Zhao, Fuel Process. Technol. 2014, 126, 199-206; e) L. R. Snowdon, J. K. Volkman, Z. R. Zhang, G. L. Tao, P. Liu, Org. Geochem. 2016, 91, 3-15.

[15] E. Nowicka, M. Sankar, R. L. Jenkins, D. W. Knight, D. J. Willock, G. J. Hutchings, M. Francisco, S. H. Taylor, Chem. Eur. J. 2015, 21, 4285-4293

[16] E. Nowicka, T. Clarke, M. Sankar, R. Jenkins, D. Knight, S. Golunski, G. Hutchings, D. Willock, M. Francisco, S. H. Taylor, Chem. Eur. J. 2018, 24,655-662

[17] B. Plietker, Synthesis-Stuttgart 2005, 2453-2472.

[18] J. Frunzke, C. Loschen, G. Frenking, J. Am. Chem. Soc. 2004, 126, 3642-3652.

[19] P. J. di Dio, S. Zahn, C. B. W. Stark, B. Kirchner, Zeitschrift Fur Naturforschung Section B-a J. Chem. Sci. 2010, 65, 367-375.

[20] M. J. Frisch, G. W. Trucks, H. B. Schlegel, G. E. Scuseria, M. A. Robb, J. R. Cheeseman, G. Scalmani, V. Barone, B. Mennucci, G. A. Petersson, H. Nakatsuji, M. Caricato, X. Li, H. P. Hratchian, A. F. Izmaylov, J. Bloino, A. V. Marenich, J. Bloino, G. Zheng, J. L. Sonnenberg, M. Hada, M. Ehara, K. Toyota, R. Fukuda, J. Hasegawa, M. Ishida, T. Nakajima, Y. Honda, O. Kitao, H. Nakai, T. Vreven, J. A. Montgomery Jr., J. E. Peralta, F. Ogliaro, M. J. Bearpark, J. J. Heyd, E. N. Brothers, K. N. Kudin, V. N. Staroverov, R. Kobayashi, J. Normand, K. 
Raghavachari, A. P. Rendell, J. C. Burant, S. S. Iyengar, J. Tomasi, M. Cossi, N. Rega, J. M. Millam, M. Klene, J. E. Knox, J. B. Cross, V. Bakken, C. Adamo, J. Jaramillo, R. Gomperts, R. E. Stratmann, O. Yazyev, A. J. Austin, R. Cammi, C. Pomelli, J. W. Ochterski, R. L. Martin, K. Morokuma, V. G. Zakrzewski, G. A. Voth, P. Salvador, J. J. Dannenberg, S. Dapprich, A. D. Daniels, O. Farkas, J. B. Foresman, J. V. Ortiz, J. Cioslowski, D. J. Fox, Gaussian09 Revision E.01, Wallingford, CT, 2009.

[21] a) C. T. Lee, W. T. Yang, R. G. Parr, Phys. Rev. B 1988, 37, 785-789; b) A. D. Becke, J. Chem. Phys. 1993, 98, 5648-5652; c) P. J. Stephens, F. J. Devlin, C. F. Chabalowski, M. J. Frisch, J. Phys. Chem. 1994, 98, 11623-11627.

[22] Y. Zhao, D. G. Truhlar, Theor. Chem. Acc. 2008, 120, 215-241.

[23] L. Goerigk, A. Hansen, C. Bauer, S. Ehrlich, A. Najibi, S. Grimme, Phys. Chem. Chem. Phys., 2017, 19, 32184-32215.

[24] P. Verma, Z. Varga, J. E. M. N. Klein, C. J. Cramer, L. Que, D. G. Truhlar, Phys. Chem. Chem. Phys,.2017, 19, 13049-13069.

[25] M. Kasai, H. Ziffer, J. Org. Chem. 1983, 48, 2346-2349.

[26] P. Peng, J. M. Fu, G. Y. Sheng, A. Morales-Izquierdo, E. M. Lown, O. P. Strausz, Energy \& Fuels 1999, 13, 266-277.

[27] K. Tabatabaeian, M. Mamaghani, N. O. Mahmoodi, A. Khorshidi, Catal. Comm. 2008, 9 , 416-420.

[28] L. M. Stock, T. Kwok-tuen, Fuel 1983, 62, 974-976.

\section{Table of Content}

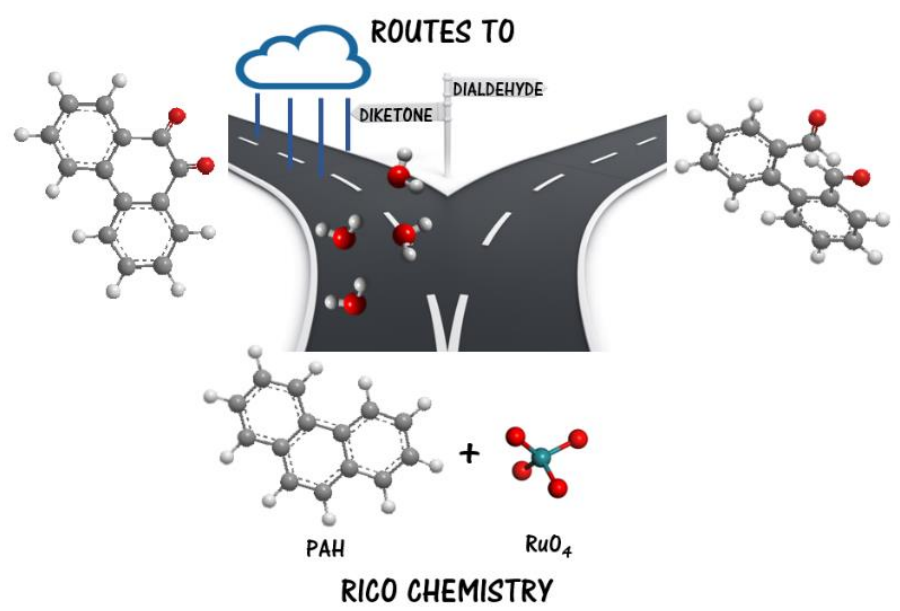

